2

\section{ABSTRACT \\ ABSTRACT}

\title{
Tests on Prototype Pretensioned Natural Stone Beams
}

\author{
Wendel Sebastian ${ }^{1}$, Steve Webb ${ }^{2}$ \\ ${ }^{1}$ Department of Civil, Environmental and Geomatic Engineering, University College London, \\ Chadwick Building, Gower Street, London WC1E 6BT, UK \\ ${ }^{2}$ WebbYates Engineers, 48-50 Scrutton Street, London EC2A 4HH
}

Stone has over millennia been used for structures which naturally develop compression under gravity loads. This study focuses on segmental stone beams with artificially induced compression. Prototype specimens were fabricated using epoxy adhesive for longitudinal shear transfer between prestressed steel strands and pre-cut Valange limestone blocks with mortar inter-block joints. Each specimen was prestressed by a single strand, to enable focus on the fundamental mechanics. Each strand was tensioned against the stone, then released after the epoxy became structurally active, so this is a form of pretensioning which eliminates external anchors and elastic shortening losses, and which enables agile construction because it can be implemented either at the factory or on site. Specimen details were informed by pullout tests. One specimen type entailed concentrically pretensioned square-section stone blocks, the other eccentrically pretensioned rectangular-section blocks. One concentric-strand specimen was strain-gauged near both ends to enable identification of the transfer zone, while an eccentricstrand specimen was instrumented at midspan with strain and displacement gauges to quantify pretensioning-induced camber and strains. Vibration tests were conducted on both specimens, then an eccentric-strand specimen was tested to ultimate in three-point flexure while a concentric-strand specimen was subjected to fire. The results reveal good damping, a high and consistent elastic modulus for the stone based alternately on local and global data, beneficial delay of cracks at the joints due to the pretensioning and protection of the epoxy by the stone over an extended period in fire. The ultimate limit state under load entailed gradual spalling of stone in the peak compression zone followed by a dominant asymmetric crack. These results strongly hint at the viability of pretensioned stone beams for low-carbon floor applications.

2 KEYWORDS : stone, prestressing, pretensioning, transfer zone, damping, fire, pullout, epoxy. 


\section{Introduction}

\subsection{Stone and prestressing}

Much of the world's historic architectural heritage is testament to the successful use of stone in construction over millennia. The structural integrity of cathedrals, bridges and other heritage stone artefacts stems from the compression-dominated mechanics of their component arches, vaults, walls, columns and flying buttresses, in turn predicated on stone's high compressive strength. Heyman [1] emphasised this point by stating that, barring flexure, instability and stress raisers, a typical construction stone column can exceed a mile in height before self-weight causes crushing.

Its excellent durability is another feature which renders stone eminently suited to heritage structures and, more recently, to cladding [2]. This durability is evidenced by the wealth of heritage structures (Stonehenge (UK), the rock-cut architecture of Petra (Jordan), Luxor Temple (Egypt), etc) which have endured centuries of weathering [3]. London's iconic buildings such as St Paul's and Westminster cathedrals along with $18^{\text {th }}$ century churches by Sir Christopher Wren were built of Portland Stone, a form of limestone which has withstood well the acute demands of the city's complex environment [4]. Alongside this evidence from long-standing structures, laboratory tests are crucial to assessing durability, for example to show that the compressive strengths of some limestones exhibit a low sensitivity to freeze-thaw action [5], and to elucidate the role of stone micro-fabric in durability [6]. More widely, multiple studies [7-10] have focused on the shortterm, long-term and fire behaviours of construction stones. In testing for mechanical properties, the anisotropy of the stone due to the bedding planes at the quarries must be considered [11].

Owing to the shift towards construction of low environmental impact, there is a resurgence of interest in natural stone as a low-carbon material for modern architecture. Stone requires only extraction at the quarry followed by transportation to and assembly at site, without the need for high energy, greenhouse gas emitting chemical transformations or treatments between source and application [11]. Hence, the embodied carbon $\left(\mathrm{kgCO}_{2} /\right.$ tonne) of limestone is about $30 \%$ and $93 \%$ less than those of reinforced concrete (RC) and steel, respectively [3]. Limestone outperforms RC and steel on durability, although steel sections for a given application may be lighter. Moreover it is estimated that, globally, at the current rate of extraction there is an 850 million year reserve of 2 stone, and that this rate of extraction is probably exceeded by the rate of new stone formation in 3 the earth's crust [12]. Also, there is a wide perception of stone as an elegant material which lends 64 an aura of quality to the internal environments of buildings. Polished stone surfaces are eye- 
catching, which removes the need for other materials to provide finishes when it is used indoors. Consequently, structural uses of stone including staircases, floor toppings and cladding have gained traction recently [11, 13-22]. Expo '92 in Seville showcased the Pavilion of the Future, which still exists and which comprises $17.4 \mathrm{~m}$ diameter stone arches on steel trusses and $28 \mathrm{~m}$ high stone columns, offering a blueprint for $21^{\text {st }}$ century architecture.

Wider applications are inhibited by a lack of specific guidance in contemporary structural design codes. Where the application entails flexure of the stone structure, reinforcing or prestressing overcomes the nominal zero tensile strength of the joints between stone blocks and indeed the low tensile strength of the stone itself (though this often exceeds the tensile strength of concrete). As a result, ad-hoc structural testing of reinforced or prestressed stone structures has been conducted $[14,15,17,19,20]$. The form of prestressing used to date is post-tensioning, with steel plates anchored against the end faces of the stone to transfer the compression into the stone structure.

The present study considers use of prestressed stone beams for floor applications. Fig. 1(a) shows a recent trial construction, now dismantled and to be re-assembled in a different layout in future for testing at the UCL structural engineering laboratory. As can be seen, the trial structure comprised two $12 \mathrm{~m}$ long post-tensioned limestone beams, with limestone slabs spanning $1.5 \mathrm{~m}$ transversely between the beams. Post-tensioning is reversible as the strands can be de-tensioned, enabling reuse of the stone. This is a sustainability benefit of post-tensioning.

In Fig. 1(a), the exposed steel plates and protruding strands seen at the near-ends of the stone beams can be problematic if space at the beam-wall joint is limited. In such cases it is useful to conceal the mechanism of strand-stone force transfer within the stone, leaving the end faces of the stone members clear of any external anchorage. This concealment is an integral feature of pretensioning.

In its application to concrete the strands are tensioned before casting, thus pretensioning. Once the concrete has cured sufficiently, the strands are released and their forces are transferred into the bulk of the concrete via a thin concrete zone around the strands. Fig. 1(b) shows the strand force profiles along the beam at the start and end of pretensioning. After release there is a transfer zone along which the strand's tensile force, and so the concrete's equilibrating compressive force, increases nonlinearly from zero at the ends to a peak at short distances inwards. Use of pullout and other tests to study the transfer zone mechanics is at the core of pretensioned concrete research [23-29].

4 Note that for pretensioning to take root, it is not sufficient for the bulk concrete to have cured. The concrete immediately surrounding each strand must also have cured, since it is this concrete which 
acts as a longitudinal shear connector (enabling force transfer) between the strand and the bulk concrete. Without curing of this concrete near the strand, there is no pretensioning even if the bulk concrete further away has cured. This idea is fundamental to the stone application. An internal strand-to-stone longitudinal shear connector is needed if the transfer mechanism is to be concealed within the stone. Epoxy adhesives show good potential for this role. The epoxy can be poured wet to flow along the hole, thereby occupying the space between the strand and the stone. On curing, the epoxy develops good adhesion to the stone and possesses good compression / shear stiffness and strength which are crucial to interaction with each released strand. Since the strand is tensioned before the epoxy becomes structurally active, this is an example of pretensioning. It is important to understand the transfer mechanics and the wider effectiveness of this application of pretensioning for the stone-adhesive-strand system. That fact has motivated the study reported in this paper.

\subsection{Comparisons between pretensioning of stone and of concrete}

In elucidating the mechanics of pretensioned stone beams (PSBs), some important differences from the more well-established pretensioned concrete beams (PCBs) should be noted, as follows :

1) For PCBs, external anchors fixed to a casting bed are needed initially to keep the strands stretched, as the wet concrete cannot perform that role, while for PSBs the stone is used initially to equilibrate the stretched strands, thus eliminating external anchors and reducing tool costs.

2) Hence PCBs can originate only at a factory, while PSBs are an agile form of construction, implementable either at a factory or in-situ. Thus for remote sites where long PCBs cannot be transported, short stone blocks can be transported in packs, sequenced and pretensioned in-situ.

3) PCBs exhibit elastic shortening losses (Fig. 1(b)) because the concrete shortens during release of the strands, but PSBs don't because the stone shortens during tensioning of the strands.

4) PCBs proceed directly to the pretensioned state, while PSBs are first post-tensioned (when the stone initially equilibrates the stretched strands) en route to the final pretensioned state.

5) The strand-to-beam shear connection is a uni-material system (the concrete) for PCBs, but is a bi-material (epoxy-stone) system with an interface between the two materials for PSBs.

6) The pretensioning process is accelerated by steam curing the parent concrete material for PCBs, and by using a rapid hardening epoxy for the shear connecting material in PSBs.

(1)


129 Prestressing has multiple benefits including precambering of the stone beam (to reduce dead and 130 live load deflections), counteracting the stresses induced in the beam by externally applied loads 131 (which can improve load capacity) and stiffening the beam (which is good for vibration behaviour, 132 etc) by using precompression to inhibit cracks at the mortar joints between stone blocks.

133 Hence the overall aim of this study is to demonstrate the successful fabrication and load testing of 134 pretensioned stone beams comprising Valange limestone blocks with mortar joints, prestressing 135 steel strands and epoxy adhesive as the strand-to-stone transfer element.

136 The specific objectives are to :

137 1) Illustrate an effective method of feeding the epoxy into the stone around the strands.

138 2) Use pullout tests to confirm the epoxy adhesive as an effective strand-to-stone shear connector.

$1393)$ Illustrate the mechanics of the transfer zone in the pretensioned stone members.

140 4) Demonstrate that these members show good vibration characteristics.

141 5) Compare elastic modulus values for the stone based on local and global measurements

142 6) Demonstrate the failure modes and load-carrying capability of the pretensioned beams.

143 7) Gain initial insight into the fire performance of this pretensioned strand-epoxy-stone system.

144 Now the standard pullout test entails an initially unstressed strand of arbitrary embedment length, 145 while a pretensioned beam entails an already tensioned strand with a distinct transfer zone. Hence 146 the pullout test doesn't quite mimic a pretensioned beam, but it is a simple test which gives a good 147 preliminary idea of the internal anchorage potential which is so fundamental to pretensioning.

148 With this in mind, the following strand-epoxy-stone specimen tests were conducted in this study:

149 1) Pullout tests on specimens of different embedment lengths.

150 2) Pretensioning, vibration and fire tests on square-section stone specimens with a concentric strand.

151 3) Pretensioning, vibration and failure tests on rectangular-section stone beams with an eccentric strand.

152 One strand was used per specimen, to enable a focus on the fundamental science. The concentric 153 strand specimens were used to elucidate the transfer zone mechanics, while the eccentric strand 154 beams enabled effects such as precamber to be assessed. In what follows the materials, specimens 155 and tests are discussed, then conclusions are drawn and avenues for future research are suggested. 


\section{Materials}

157 Valange is an oolitic limestone quarried in the commune of Massangis, located in North central

158 France. It is off-white in colour, with veins and including fossil fragments, Fig. 2(a), (b). The

159

160

161

162

163

164

165

166

167

168

169

170

171

172

173

174

175

176

177

178

179

180

181

182

183

184

185

186 supplier quoted properties for Valange include a compressive strength of $73 \mathrm{~N} / \mathrm{mm}^{2}$ and modulus of rupture of $7.5 \mathrm{~N} / \mathrm{mm}^{2}$ [30]. Samples weighed in the study reported in the present paper gave a density of $2400 \mathrm{~kg} / \mathrm{m}^{3}$. No elastic modulus was given by the supplier, but a value of 28.9 $\mathrm{kN} / \mathrm{mm}^{2}$ was deduced from the present study as described in Section 6.0 of this paper.

The adhesive used was a thixotropic two-part epoxy. The manufacturer (Parex) gives a pot life of $25 \mathrm{mins}$ at $20^{\circ} \mathrm{C}$, compressive strength of $70 \mathrm{~N} / \mathrm{mm}^{2}$ at 7 days, tensile, flexural and slant shear strengths of $26 \mathrm{~N} / \mathrm{mm}^{2}, 58 \mathrm{~N} / \mathrm{mm}^{2}$ and $55 \mathrm{~N} / \mathrm{mm}^{2}$ respectively, and a $3.6 \mathrm{kN} / \mathrm{mm}^{2}$ elastic modulus [31]. Parex walling mortar was used to make $4 \mathrm{~mm}$ thick mortar joints between consecutive stone blocks in the specimens. The manufacturer's data for this mortar include a pot life of 45 mins, compressive strength of $35 \mathrm{~N} / \mathrm{mm}^{2}$ at 7 days and a $7 \mathrm{~N} / \mathrm{mm}^{2}$ flexural strength [31].

The prestressing steel was a seven-wire smooth surface strand of $15.7 \mathrm{~mm}$ diameter, 1860 $\mathrm{N} / \mathrm{mm}^{2}$ tensile strength, $150 \mathrm{~mm}^{2}$ section area and a maximum force of $321 \mathrm{kN}$ peak value.

In making one of the rectangular-section beams, a cartridge was used to inject the adhesive via a side hole drilled into the mortar joint between the two middle stone blocks. This side hole ran perpendicular to and intersected the main $20 \mathrm{~mm}$ diameter hole drilled longitudinally into the stone blocks for feeding the prestressing steel strand through. Hence the adhesive travelled a short distance $(65 \mathrm{~mm})$ along this side hole, then turned through $90^{\circ}$ and flowed in both directions along the main hole to fill the gap between the strand and the stone wall of the main hole. Some adhesive would also have seeped into the pores of the stone through the wall of this main hole, which would have provided the adhesive with some keying action into the stone.

Fig. 2(c) shows a short length of Valange stone which fractured off a beam specimen during a failure test. Note the middle strip of a different colour, which is the hardened adhesive that originally encircled the lower half of the steel strand and which (namely the adhesive) is still embedded in the stone. The inclined grooves in the adhesive are from the wires of the strand, which shows how closely the adhesive fitted around the strand. Overall the image shows that the adhesive flowed into and cured well in the main hole, in the process developing good bond with the stone. These are all testament to the success of the cartridge injection of the adhesive. 


\subsection{Pullout tests}

\subsection{Setup and procedure}

The pullout tests were conducted using individual Valange stone blocks of $150 \mathrm{~mm}$ x $150 \mathrm{~mm}$ square cross section. Four different embedment lengths were tested, namely $200 \mathrm{~mm}, 400 \mathrm{~mm}$, $600 \mathrm{~mm}$ and $800 \mathrm{~mm}$, henceforth named the P200, P400, P600 and P800 specimens respectively.

Fig. 3(a) shows the generic details at the pulling end. An open box fabricated from welded steel plates was used to equilibrate the force from the jack which pulled on the strand, by transmitting this force to the front face of the Valange stone block. To allow passage of the prestressing strand, a hole was drilled through the front face plate of the box (against which the jack reacted) and a horseshoe shape was cut out of the back face plate (which reacted against the stone) of this steel box. A pancake load cell placed between the jack and the front face plate of the box was used to measure the force from the jack. In addition, two L-shaped steel plates were bolted to each other, effectively clamped, around the strand to form a $T$ within the free space of the steel box. Strand-stone slip at the pulling end of the block was measured by two displacement transducers which at their back ends were fixed to the sides of the Valange block via magnetic bases and bonded steel plates, and which at their front ends touched the outstanding arms of the L-shaped plates. The pulling end slip was taken as the mean of the two transducer readings.

Fig. 3(b) shows the actual test setup for specimen P600. The hydraulic jack was activated by manual pumping of oil from a nearby reservoir. During the test, the jack load was gradually increased by steady pumping, while the load cell and transducer readings were recorded at $1 \mathrm{~Hz}$ continuously into an electronic data acquisition system until failure occurred.

\subsection{Results and discussion}

In all cases the bond between the strand and adhesive failed, while the adhesive-stone bond appears to have remained intact. For specimens P200 and P400 there were audible cracking sounds as failure by significant strand-adhesive slip was approached. The left image of Fig. 4(a) shows specimen P400 after failure, note the clear length of pulled out strand without adhesive. For specimens P600 and P800 loud bangs were heard at ultimate. In addition splitting cracks appeared along P600, see the right image of Fig. 4(a) which also shows a small truncated cone of Valange stone pulled off at the front end of the block. 
217 Fig. 4(b) shows the pullout force vs slip plots for all specimens. The plots show a high initial

218 stiffness followed by nonlinear behaviour and a ductile plateau for specimen P200, with a near 219 ductile plateau for specimen P400. Specimens P600 and P800 show sharp drops in load after 220 the peak, although P600 stabilised at high slip, showing a semblance of a ductility plateau.

221 Fig. 4(c) shows how the mean bond stress, defined as the quotient of the pullout force and the

222 bonded surface area of the bar along the entire embedment length, varied with slip for each pullout specimen. It is evident that the peak mean bond stress is quite similar for all four specimens, falling within a narrow range from $4.6 \mathrm{~N} / \mathrm{mm}^{2}$ for P400 to $5.5 \mathrm{~N} / \mathrm{mm}^{2}$ for P200. Indeed, the entire pre-peak curves for P400, P600 and P800 closely resemble each other, with that for P200 in good proximity to the others. Such consistency hints at good quality control on both the materials and workmanship used to fabricate the pullout specimens.

Fig. 4(d) shows the pullout load capacity plotted as a function of embedment length. A linear relationship is evident, with a mean gradient of $245 \mathrm{kN} / \mathrm{m}$ length of strand. Now pullout capacity tends to level off beyond a threshold embedment length. Fig. 4(d) shows that this threshold was not reached in the tests, suggesting that even more pullout capacity than the $196 \mathrm{kN}$ achieved at $800 \mathrm{~mm}$ embedment length might've been possible at longer embedments. Further tests are needed to establish this threshold embedment length, beyond which the mean shear bond stress vs slip curves will drop relative to those shown in Fig. 4(c).

These pullout test results provided encouragement for taking the next step, namely to fabricate Valange stone beams with a pretensioning level per strand of about $200 \mathrm{kN}$, which is about $70 \%$ of the strand's characteristic maximum force.

\subsection{Transfer specimen}

\section{1 - Specimen setup and instrumentation}

Two concentrically pretensioned specimens were used to understand the transfer zone mechanics of the strand-epoxy-Valange stone system. Fig. 5(a), (b) show the details of these specimens. As can be seen, each specimen was of $150 \mathrm{~mm}$ x $150 \mathrm{~mm}$ square cross section, with a single concentric prestressing strand, and $3.5 \mathrm{~m}$ long. This length was informed by the rough guide which emerged from the pullout tests described above. 
246 Each specimen was fabricated using five $700 \mathrm{~mm}$ long pre-cut Valange stone blocks. Mortar

247 joints, each $4 \mathrm{~mm}$ thick and comprising the mortar described previously, was used between stone

248 blocks. The mortar was left for a week to cure before the prestressing operation took place.

249 Fig. 5(a), (b) show that at multiple sections near both ends of one specimen, longitudinally

250

251

252

253 oriented strain gauges were placed at the centres of all four faces. This enabled the mean strain at each such section to be evaluated, which in turn enabled plotting of the mean strain profile along the block both at the strand stressing and strand release stages. The strain gauged section labelled S1 in Fig. 5(a) will be focused on shortly in this paper. Meanwhile note that the use of a single concentric strand was a move to try and ensure as near as possible uniform stress on each section. Hence this specimen and instrumentation setup were ideally suited to understanding the transfer zone mechanics for this pretensioned system.

\section{2 - Pretensioning operation}

Fig. 5(c), (d) show the pretensioning setup. Fig. 5(c) in particular also shows the strain gauges already installed at the black taped locations. The 7-wire strand had already been fed through the $20 \mathrm{~mm}$ diameter hole pre-drilled through the blocks. At the near-end in Fig. 5(c), it is evident that the strand has been locked into place by a barrel-and-wedge system which in turn reacts against two thick steel plates with large diameter studs between them. The outer plate directly equilibrated the load coming through the barrel, while the inner plate distributed the load in bearing to the end face of the stone specimen via a thin rubber pad. Fig. 5(d) shows the pulling end, which was similar except for the presence of the jack and the load cell.

The pretensioning operation progressed at the jacking end in four key stages, as follows :

1) Zero all strain gauges, then set the data logger to record strains and loads at $1 \mathrm{~Hz}$ continuously.

2) Tension the strand by loading the jack using a manual pump connected to an oil reservoir.

3) On reaching $200 \mathrm{kN}$ jack load, drive the wedges firmly into the barrel to grip the strand.

4) The jack is unloaded to release (and hence de-tension the exposed length of) the strand.

2 Fig. 6(a) shows the strain vs jack force plots for section S1 identified in Fig. 5(a). Three key conclusions from this plot are as follows :

1) After an initial nonlinear bedding-in regime at low loads, the behaviour was linear. 
297 298 299 300

2) Three faces developed similar strains, the fourth face developed only $14 \%$ less strain than the others. This justifies an assumption of uniform mean strain at the section.

3) The unloading lines were linear and parallel for all four strains.

The dashed lines of Fig. 6(a) show how the mean of the four strains at S1 varied during both loading and release stages. Later in this paper this plot, which represents local elastic behaviour of the Valange stone, will be used to estimate an elastic modulus value for the material.

After release, the epoxy adhesive was then pumped into the longitudinal hole in the stone around the strand, left to cure for ten days and finally the strand was completely de-stressed by slightly and gradually pulling on the strand with the jack so that the barrel-and-wedge system could be dismantled. At that stage all of the force was transferred from the strand to the stone via the cured adhesive connection along this hole occupied by the strand in the stone. Data logging continued for some time after initial transfer.

Fig. 6(b) shows the final mean strain profile (using the absolute values of the strains) recorded along the specimen. Two key points from this plot are as follows:

1) There is some asymmetry about the specimen's mid-length and the reason for the slightly higher strain near mid-length is not clear, but these deviations from the ideal are modest and the plot overall shows a strong semblance to a uniform specimen's strain profile at transfer.

2) The left and right sides show transfer lengths of $600 \mathrm{~mm}$ and $800 \mathrm{~mm}$ respectively. For comparison with concrete, it may be noted for example that transfer lengths of $582 \mathrm{~mm}$ and $463 \mathrm{~mm}$ were obtained for $12.7 \mathrm{~mm}$ diameter, seven-wire strands pretensioned to $184 \mathrm{kN} \mathrm{jack}$ load in concretes of compressive strengths $23 \mathrm{~N} / \mathrm{mm}^{2}$ and $36 \mathrm{~N} / \mathrm{mm}^{2}$ respectively [29].

These results confirm that pretensioning based on use of an epoxy adhesive as the longitudinal shear connector between the strand and the stone was successful. The transfer lengths are reasonable for a realistic level of strand pretensioning force (namely $70 \%$ of the characteristic ultimate force that the strand can carry), and the final release strain profile suggests that both the epoxy adhesive shear connector and the stone may be regarded as homogenous.

\subsection{Vibration tests}

The strain gauged pretensioned specimen was supported near its ends and excited by thumping it with a mallet at midspan. A short length of timber was used at midspan to soften the blow and 
avoid breaking off pieces of the stone. Data logging of the strain gauges at $1.2 \mathrm{kHz}$ started just before thumping and continued for $30 \mathrm{~s}$ after thumping, to capture the impulse response.

Fig. 7(a) shows the strain vs time plot for a gauge near midspan. A Fast Fourier Transform of the data is shown in Fig. 7(b), revealing a clear fundamental natural frequency of $19.9 \mathrm{~Hz}$, which is used later in this paper as a global basis for estimating the elastic modulus of the stone.

The positive amplitude points in Fig. 7(a) were plotted against their corresponding times. The result is Fig. 7(c). Note also the best-fit exponential curve drawn through the points. The logarithmic decrement, $\delta$, which reflects the rate of decay of the oscillations, is defined as [32] :

$$
\delta=(1 / \mathrm{N}) \ln \left(\mathrm{X}_{0} / \mathrm{X}_{\mathrm{N}}\right)
$$

where $\mathrm{X}_{0}$ and $\mathrm{X}_{\mathrm{N}}$ are amplitudes of motion separated by $\mathrm{N}$ cycles. Now using the equation of the exponential approximation as given on Fig. 7(c), if the times of occurrence of the amplitudes are $t_{0}$ and $t_{N}$ respectively, then the following apply, namely :

$$
\mathrm{X}_{0}=34.244 \mathrm{e}_{0}^{-4.695 \mathrm{t}} \quad \text { and } \quad \mathrm{X}_{\mathrm{N}}=34.244 \mathrm{e}^{-}{ }^{4.695 \mathrm{t}} \mathrm{N}
$$

Combining Eqns (1) and (2) leads to the following, namely :

$$
\delta=4.695\left(\mathrm{t}_{\mathrm{N}}-\mathrm{t}_{0}\right) / \mathrm{N}
$$

Now between the start and end of the plot as presented in Fig. 7(c), $N=8$ and the time interval $\left(t_{N}-t_{0}\right)$ is $0.409167 \mathrm{~s}$. These numbers lead to a $\delta$ value of 0.24013 . Then, the following equation relates the specimen's damping constant, $\zeta$, to the logarithmic decrement, namely [32] :

$$
\zeta=\delta /\left[4 \pi^{2}+\delta^{2}\right]^{1 / 2}
$$

Using $\delta=0.24013$ in this equation gives a damping constant of 3.8\%. Fig. 7(c) also shows the amplitude decay and associated best-fit exponential plots based on the strain vibration data for the instrumented eccentric-strand specimen discussed later in this paper. Processing of these 
latter plots as above gives a damping constant of $3.5 \%$, showing good consistency with the above value.

\subsection{Fire testing}

Fig. 8(a) shows the specimen being subjected to a preliminary fire test outdoors. This was done after the above pretensioning operation and vibration test had been conducted. As can be seen, the specimen was supported near its ends at height, with the middle block subjected to fire from a drum directly below it. The fire was fuelled with wood thrown in via the top of the drum and air fed from an airline through a pipe at the base of the drum. The test lasted almost 2.5 hours.

No explosive failure of the prestressed specimen was observed throughout the test. At about 85 minutes into the test longitudinal cracking was observed on the top face of the middle block, see Fig. 8(b). Soon after these cracks were first seen, an extra thin flame was observed to pour out of the top crack. This suggests that the crack had extended from the surface to the central hole, in the process creating a path for burning of the epoxy from within that central hole to emerge at the top surface. It may be that the similar crack on the bottom face of the stone had also extended to the hole at the core, thereby providing a direct, uninhibited path for the heat of the flame to have accessed and burnt the epoxy. In order to better understand this occurrence, future work may consider the fire-induced thermal stresses in the stone that lead to such cracking.

After the test was over, an approximately $2 \mathrm{~mm}$ thick layer was found to have peeled off the bottom face of the middle Valange block which was directly above the fire, Fig. 8(c). Observe also the longitudinal crack on that face, which might've channelled the heat of the flame directly up to the epoxy. Finally, the portions of stone which were directly above and near the fire were broken up with a big hammer to reveal samples of stone, e.g. Fig. 8(d), containing the epoxy adhesive around the strands at the core of the cross section. It is seen that the lower part of the right hand sample (which was nearer the fire) experienced burning of the adhesive, and also that a short length over the upper part of that sample shows the adhesive changing colour from its original white to a yellow-orange, indicating that this short length of adhesive too was near burning. The sample of Valange on the left of the photo shows adhesive exhibiting a healthy white resin colour, hence this portion of adhesive remained intact throughout the fire.

Fig. 8(e) shows the temperature variations recorded from the middle Valange block (which was directly above the fire), using high temperature-resistant thermocouples placed at two locations 
of the block as shown on the diagram drawn within the plot. It is seen that one thermocouple was placed just under the surface of a vertical face of the block, while the other thermocouple was located about $5 \mathrm{~mm}$ above the core longitudinal hole in that block. Henceforth these nearsurface and near-core thermocouples will be referred to as NS and NC respectively. In future, the NC thermocouple could be placed just below the core, in the direct path of heat coming upwards from the fire through the stone, while the NS thermocouple could be placed just above the bottom face where higher temperatures would very likely be experienced. The following points emerge from Fig. 8(e) :

1) The NS temperature started rising rapidly after only 2 minutes, while NC started rising at a much lower rate and only after 10 minutes when NS had already exceeded $210^{\circ} \mathrm{C}$.

2) The NS temperature then rose nonlinearly up to a peak of $700^{\circ} \mathrm{C}$ after about 1.75 hours, while the $\mathrm{NC}$ temperature rose almost linearly up to a peak of $480^{\circ} \mathrm{C}$ after circa 2.25 hours.

3) The NC temperature continued to rise even for another 20 minutes after the NS temperature dropped towards the end of the test, because there was still heat flow from the surface through the material to the core.

4) After almost 2 hours the NS temperature started to fall owing to exhaustion of the wood fuel, but the internal (NC) temperature continued to rise. After 2.25 hours when the test was concluded, the NS temperature had dropped to about $100^{\circ} \mathrm{C}$. At this stage water was thrown over the specimen, inducing a thermal shock which exacerbated the above cracking and peeling.

5) The sudden and large drop in NS temperature about 40 minutes into the test was resolved by feeding more wood fuel to resurrect the fire.

That the inside of the stone, including the adhesive at its core, lagged so much behind the outside in temperature means that the Valange stone served as a good insulator. Further tests should be conducted to establish minimum surface-to-adhesive distances needed to protect the adhesive, as a function of the surface temperature in fire.

\subsection{BEAM SPECIMENS}

\section{1 - Beam specimen setup and instrumentation}

Two eccentrically pretensioned beam specimens were fabricated and tested. One of the beams was strain gauged as shown in Fig. 9. Key features of the beams and instrumentation are as follows : 
1) Each beam was of 150 wide $\mathrm{x} 300 \mathrm{~mm}$ deep section, and $4220 \mathrm{~mm}$ long, made by sequencing six Valange blocks each of $700 \mathrm{~mm}$ length with $4 \mathrm{~mm}$ thick mortar inter-block joints.

2) The single strand was at $50 \mathrm{~mm}$ eccentricity below the centroid of the section. In theory this created a pretensioning stress distribution entailing zero stress at the top of the section and maximum compressive stress at the base. The target pretensioning strand force was $200 \mathrm{kN}$.

3) Three blocks were strain gauged (see below), each at its mid-length.

4) On one of the blocks adjoining midspan, longitudinal strain gauges were placed at three different levels, namely on the soffit (SG1), at mid-depth (SG2, SG3) on both vertical faces and near the top (SG5, SG6) also on both vertical faces. The net strain at each of the two highest levels was taken as the mean of the readings from the two gauges at that level.

5) Gauge SG6 was placed on the soffit of the block on the other side of midspan, to enable checks on symmetry of load response by comparison with readings from gauge SG1.

6) One end block was strain gauged (SG7, SG8) at mid-depth on both vertical faces, to provide results for comparison with the gauges (SG2, SG3) placed at the same level on the block near midspan during the pretensioning operation.

The beams were first pretensioned using the same operation previously described for the square section, concentric-strand specimens, with one minor exception. While for the concentric-strand specimens only one pulling cycle was used to anchor the strand force against the end stone block, for the eccentric-strand specimens two pulling cycles were used. This is discussed further below.

In what follows, results are presented for the pretensioning operation on the strain-gauged beam, after which the failure mode and load under three-point bending are discussed for the beam which wasn't strain gauged, and finally the behaviour of the strain-gauged beam up to advanced stages of nonlinearity also under three-point bending is discussed.

\subsection{Pretensioning operation}

As for the square section, concentrically prestressed specimens, the pulling jack force and strain gauge readings were recorded at $1 \mathrm{~Hz}$ during the prestressing operation. The upward deflection at midspan due to the eccentricity of the pretensioning force was also recorded. Fig. 10(a) shows how this upward movement at midspan varied with jack force. There is pronounced nonlinearity up to about $100 \mathrm{kN}$ force, possibly due to friction within the system, then linear behaviour up to the peak force of $180 \mathrm{kN}$. At this point the wedges were driven back into the barrel at the jacking end so as to grip the strand at that end, following which the jack was unloaded. The plot shows that during 
this unloading phase the deflection dropped nonlinearly as a function of jack force (due to draw-in of the strand within the barrel-wedge system), losing about $30 \%$ of the peak deflection when the jack was fully unloaded. In an attempt to increase the residual upward midspan deflection further, the jack was reloaded, this time up to $200 \mathrm{kN}$. Fig. 10(a) shows that, during this final pull, the deflection remained unchanged until the vertical reloading line intersected the original loading characteristic, at which point the deflection started to increase again because the wedges were loosened from the barrel, removing their grip on the strand. This second load-deflection curve is seen to have been palpably steeper than its predecessor. Then the wedges were again driven in and the jack was unloaded a second time, again producing a nonlinear unloading characteristic. Although the second peak jack load exceeded the first by about $10 \%$, the second (and final) residual deflection exceeded the first by only $5 \%$.

Fig. 10(b) shows that the variations with jack force of the mean strains at the three gauged levels near midspan broadly follow that of the midspan deflection. Also, Fig. 10(b) confirms that this phase of the below-centre eccentric prestressing operation did achieve the desired outcome of peak compressive strain on the section at the base of the beam, modest compressive strain at mid-depth and low compressive strain near the top. No cracking / crushing of the mortar joints was observed.

Now once the second pulling operation was complete, the adhesive was injected into the beam around the strand and left to cure over 10 days. At the end of the curing period, the barrel-wedge system at the pulling end was gradually loosened to enable transfer. Fig. 10(c) shows the variation over time of all recorded strains, from not long before the wedges were released up to 30 minutes later, well after the wedges were released and equilibrium was attained at the transfer stage. The wedges were released circa 5 minutes $(300 \mathrm{~s})$ into the plot. It is seen that wedge release affected none of the gauge readings from the midspan zone, but led to distinct changes in the SG7, SG8 gauge readings from near the ends because these latter gauges were in the transfer zone. The plot shows that there was subsequently only marginal creep of the SG7 / SG8 readings, to values which stabilised by the end of the plot. Overall, there was roughly a $50 \mu \varepsilon$ change in strain at $350 \mathrm{~mm}$ from one end of the beam at transfer. This modest change, along with the almost zero strain change at midspan, points to a very effective epoxy adhesive shear connection between the strand and stone.

\subsection{Failure mode in three-point bending}

Of the two eccentrically pretensioned specimens the one which was not instrumented, except for the presence of the load cell, was loaded to failure in three-point bending. Fig. 11(a) shows the test 
setup. Cracking of the mortar joint between blocks at midspan was first observed at about $40 \%$ of the failure load. This delay of the cracking (relative to zero cracking load for no pretressing) is clearly beneficial to serviceability behaviour in practice. Fig. 11(b) shows that the mode of failure, which occurred at $52 \mathrm{kN}$, was asymmetric about midspan. It was defined by a single dominant crack which progressed from the midspan loading location at an inclination through the nearest Valange block, until this crack reached the level of the strand, at which point it propagated almost horizontally to the near end of the beam. In effect, the strand-adhesive system served as a defect which triggered the horizontal crack. Fig. 11(b) also shows spalling of a large chunk of Valange stone in the flexural compression zone under the midspan load. These features suggest a combined flexural-shear failure of the beam. Also, that the crack propagated undisturbed across blocks is testament to the high degree of continuity provided between blocks by the strand and the mortar joints. This form of failure crack has previously been reported for reinforced concrete block masonry beams [33]. Future studies may consider whether the formation of this crack might be delayed using internally anchored vertical bars within the stone blocks.

As Fig. 11(c) shows, at midspan, towards failure pronounced separation (cracking) was observed at the left mortar - stone block interface near the base of the beam. Higher up this mortar joint the mortar-stone interface remained broadly intact and no crushing of the mortar was observed. In Fig. 11(c), the vertical strand was part of the loading setup at midspan, right next to the mortar joint of interest, hence its appearance and the oblique angle of the image.

The instrumented beam was similarly loaded in three-point bending. For this test from the unloaded state up to an advanced stage of loading into the nonlinear regime, Fig. 12 shows the variations with time of the total strains recorded from gauges SG4 and SG5 in Fig. 9, which were on opposite vertical faces near the top of one stone block adjacent to midspan. It is seen that at the start of the test there was the residual compressive strain of about $45 \mu \varepsilon$ from the prestressing operation. As the load applied to the beam increased, the compressive strains increased nonlinearly with time. A disparity between the strains on Fig. 12 is evident, with SG4 having been about 20\% less than SG5 towards the end of the recording period. Now Fig. 10(c) shows that the strains at these two locations were almost identical during the pretensioning operation, when the force in the strand was symmetric with respect to the width of the specimen. This suggests that the stone material was homogenous across the width of the gauged block. Hence, the across-width asymmetry evident from Fig. 12 may have been due to uneven loading across the width of the beam rather than to material asymmetry across the same. 
494 Fig. 12 shows that SG5 recorded compressive strains up to $1100 \mu \varepsilon$. If the stone was within its

523 Which may be re-written as follows :

\subsection{Global estimates}

3

\subsection{Estimates of elastic modulus of Valange stone}

As stated earlier, prestressing improves serviceability performance by precambering and by enhancing section stiffness through crack reduction or elimination. Thus, quantification of the stone's elastic modulus is important. In what follows, some of the test data presented above are used to estimate this modulus. Crucially, these estimates are based alternately on local and global aspects of structural action. Both the square section concentric-strand and rectangular section eccentric-strand specimens are used, to illustrate the consistency of the results across specimens.

Two elements of data were used to estimate global elastic modulus values for the Valange stone. One was based on the midspan deflection of the rectangular section specimen due to the eccentric pretensioning force. The other relied on the natural frequency of the concentric-strand specimen.

During the jacking operation on the strand, the below-centroid eccentricity of the pretensioning force induced a negative section moment that in turn precambered the rectangular section specimen. Recall that the associated upward deflection was measured during the test and is plotted against the jacking force in Fig. 10(a). Since the measurements started when the jacking operation began, selfweight deflections are excluded. For the purposes of the present calculation it is the linear zone, and hence upper part of the first pull operation on the plot of Fig. 10(a), which is of interest. Assume that throughout the beam, i.e. globally, E and I are the elastic modulus of the Valange stone and the second moment of area of the uncracked stone section respectively, with L being the span of the beam, $\mathrm{P}$ is the pretensioning (jacking) force and e is the eccentricity of this force with respect to the section centroid. For a midspan deflection of $\Delta_{\text {mid }}$, and recalling that $\mathrm{M}=\mathrm{Pe}$, beam theory gives :

$$
\Delta_{\text {mid }}=\mathrm{ML}^{2} /(8 \mathrm{EI})=\mathrm{PeL}^{2} /(8 \mathrm{EI})
$$




$$
\mathrm{E}=\left(\mathrm{P} / \Delta_{\mathrm{mid}}\right)\left(\mathrm{eL}^{2} /[8 \mathrm{I}]\right)
$$

526

527 In the present approach $\left(\mathrm{P} / \Delta_{\text {mid }}\right)$ is taken as the gradient of the line joining points of ordinates

$528110 \mathrm{kN}$ and $170 \mathrm{kN}$ on the first rising characteristic of Fig. 10(a), while e $=50 \mathrm{~mm}, \mathrm{~L}=4220$

$529 \mathrm{~mm}$, and $\mathrm{I}=150 \times 300^{3} / 12=3375 \times 10^{5} \mathrm{~mm}^{4}$. Quantifying that linear gradient from the plot,

530 then inserting this gradient and the values of the other symbols into Equation (6) leads to an E

531 value of $28.8 \mathrm{kN} / \mathrm{mm}^{2}$. This calculation assumes that the mortar joints made for full continuity

532 between the Valange stone blocks, which is justified by the plots of Fig. 10(b) indicating

533 compression through the entire depth of the stone section and the stiffness of the mortar joints.

534 The second global estimate of E uses the natural frequency of the square-section specimen 535 consistent with the plot of Fig. 7(b). The following expression applies to the first natural 536 frequency (pertinent to the half sine wave mode shape) of a beam of uniform mass per unit length: 537

$$
f=(\pi / 2)\left[E I /\left(q L^{4}\right)\right]^{0.5}
$$

539

540 where $\mathrm{f}$ is natural frequency, $\mathrm{E}$, I and L have their previous meanings, while q refers to the mass per unit length. This may be re-written to give :

542

$$
E=\left(4 f^{2} / \pi^{2}\right)\left(q L^{4} / I\right)
$$

544

545 Now Fig. 7(b) gives $\mathrm{f}=19.9 \mathrm{~Hz}$, while $\mathrm{I}=0.15^{4} / 12=.0000421875 \mathrm{~m}^{4}, \mathrm{q}=2400 \times 0.15^{2}=54$ $546 \mathrm{~kg} / \mathrm{m}$, and in this case the supports were moved short distances in from the ends to ensure the 547 vibrating member didn't fall of either support, giving $\mathrm{L}=3.45 \mathrm{~m}$. These numbers into Equation 548 (8) lead to $\mathrm{E}=29.1 \mathrm{kN} / \mathrm{mm}^{2}$.

551 The locally-based estimates of $\mathrm{E}$ are predicated on the section strains recorded from the 552 instrumented concentric-strand and eccentric-strand specimens during their pretensioning 553 operations. First, recall Fig. 6(a), which shows for the concentric-strand specimen how the mean of 
560

561 which, on re-writing, gives:

562

563

564

565

566

567

568

569

570

571

572

573

574

575

576

577

578

579

581

582

584

four strain gauge readings (one per face) at one section developed with jack force. Again the gradient of the linear, and hence upper part of the plot applies. If on this linear portion a strand force increment $\mathrm{P}$ induces a mean strain increment $\varepsilon$, then assuming a constant section area $\mathrm{A}$ the following applies:

Which on rewiting, gives:

$$
\mathrm{E}=(\mathrm{P} / \varepsilon) / \mathrm{A}
$$

$(\mathrm{P} / \varepsilon)$ is taken as the gradient of the line joining points of ordinates $40 \mathrm{kN}$ and $180 \mathrm{kN}$ on the rising portion of Fig. 6(a). Along with $\mathrm{A}=150^{2}=22500 \mathrm{~mm}^{4}$, an $\mathrm{E}$ value of $28.4 \mathrm{kN} / \mathrm{mm}^{2}$ is obtained.

Finally, recall that Fig. 10(b) shows strain variations with jacking force for three levels within the stone section for the eccentric-strand specimen during the jacking stage of pretensioning. The strain at the base of the beam (SG1) was the largest of the three and so is used here as it very likely incorporated the least error. At the risk of repetition, the linear upper zone of the SG1 plot is relevant. Now assuming the section of be of depth $d$, this strain gauge SG1 was at distance $d / 2$ vertically from the section's centroid. So using beam theory and the symbols with their meanings as above, the following equations for the stress $\sigma_{b}$ and strain $\varepsilon_{b}$ at the base of the beam apply:

\section{4}

$$
\sigma_{\mathrm{b}}=\mathrm{E} \varepsilon_{\mathrm{b}}=\mathrm{P}[1 / \mathrm{A}+\mathrm{ed} / 2 \mathrm{I}]
$$

which, on re-writing, gives the following equation for $\mathrm{E}$ as a function of the other parameters:

$$
\begin{aligned}
& 578 \mathrm{E}=\left(\mathrm{P} / \varepsilon_{\mathrm{b}}\right)[1 / \mathrm{A}+\mathrm{ed} / 2 \mathrm{I}] \\
& 579 \\
& 580 \text { Now }\left(\mathrm{P} / \varepsilon_{\mathrm{b}}\right) \text { is taken as the gradient of the line joining the points with ordinates } 40 \mathrm{kN} \text { and } 140 \mathrm{kN} \\
& 581 \text { on the first rising characteristic for SG1 on Fig. } 10(\mathrm{~b}) \text {, while } \mathrm{A}=150 \times 300=45000 \mathrm{~mm}^{2} \text { and } \mathrm{d}= \\
& 582300 \mathrm{~mm} \text {, with e and I assuming their values (in } \mathrm{mm} \text { and } \mathrm{mm}^{4} \text { units respectively) as stated earlier for } \\
& 583 \text { this rectangular section beam. The result is an } \mathrm{E} \text { value of } 29.4 \mathrm{kN} / \mathrm{mm}^{2} \text {. }
\end{aligned}
$$




\subsection{Discussion of results}

Table 1 summarises the E values obtained by the four different calculations listed above. As shown, a mean $\mathrm{E}$ value of $28.9 \mathrm{kN} / \mathrm{mm}^{2}$ and a CoV of only $1.3 \%$ are the results. These results emerged from local and global data, from both the concentric-strand and eccentric-strand specimens, and from both vibration and quasi-static test data. In future these tests may be backed up by axial tests on instrumented cylindrical Valange stone specimens. The consistency of these results hint at the validity of assumptions such as undisturbed continuity provided by the mortar joints between Valange stone blocks, which in turn points to the high effectiveness of the pretensioning operation in fully compressing these mortar joints made of material of good stiffness.

This elastic modulus value of $28.9 \mathrm{kN} / \mathrm{mm}^{2}$ for Valange limestone from France sits between the values of $13.9 \mathrm{kN} / \mathrm{mm}^{2}$ found for Sanliurfa limestone from Turkey [5] and and $62.3 \mathrm{kN} / \mathrm{mm}^{2}$ found for Piobbico-Cesana limestone from Italy [7]. It also sits within the narrower range between values of $27.1 \mathrm{kN} / \mathrm{mm}^{2}$ and $38.3 \mathrm{kN} / \mathrm{mm}^{2}$ found for two different types of sandstones [7]. More widely, the elastic modulus can vary significantly for different versions of nominally the same form of stone, e.g. values of $10.48 \mathrm{kN} / \mathrm{mm}^{2}$ and $57.1 \mathrm{kN} / \mathrm{mm}^{2}$ have been given for different marbles in separate studies [7, 19]. For the Valange limestone, axial tests on strain gauged cylinders will be useful for gathering statistically significant data on the full-range constitutive behaviour in compression, from which properties such as elastic modulus may be further quantified with confidence.

\subsection{Conclusions and Further Work}

In this study, four Valange stone beams with mortar joints have been successfully pretensioned using steel strands internally anchored within the stone by a two-part epoxy adhesive. Further work should be done to establish whether the specific outcomes of this study as presented below are more widely applicable.

1) The use of cartridges to inject the adhesive from small side holes in the mortar joints between Valange blocks enabled good flow of this adhesive along distances up to $2 \mathrm{~m}$ around the prestressing strands. Samples of stone from failed specimens revealed excellent cured adhesive which had bonded well to the stone and had packed tightly around the strands' wires.

2) Pullout specimens failed by strand-adhesive slip which was ductile for the shorter (200 \& 400 $\mathrm{mm}$ long) specimens, with a peak pullout load of $196 \mathrm{kN}$ for the longest $(800 \mathrm{~mm})$ specimen. These values gave confidence in use of the adhesive for pretensioning the stone beams. 
$6163)$ Strains recorded in this study from the stone during concentric-strand pretensioning revealed transfer lengths of $600 \mathrm{~mm}$ and $800 \mathrm{~mm}$. This should be compared with transfer lengths of almost $600 \mathrm{~mm}$ and $500 \mathrm{~mm}$ obtained in previous studies, for strands of $20 \%$ less diameter used to pretension concretes of 23 and $36 \mathrm{~N} / \mathrm{mm}^{2}$ compressive strengths.

620 4) Vibration tests revealed 3.5\% and 3.8\% damping for both concentrically and eccentrically pretensioned specimens respectively. This level of damping is useful for floors in buildings.

622 5) A mean elastic modulus of $28.9 \mathrm{kN} / \mathrm{mm}^{2}$ was estimated for the Valange stone along the spans of the specimens. This modulus value was highly consistent between estimates based on local (strain) and global (deflection) test data, for both the concentric-strand and eccentric-strand specimens, and from both the quasi-static pretensioning operation and the vibration tests.

6) Fire testing was conducted on a $150 \mathrm{~mm} \times 150 \mathrm{~mm}$ square section concentric-strand specimen. The near-surface temperature rose nonlinearly to $700^{\circ} \mathrm{C}$ after 1.75 hours while the temperature near the centre rose slowly and linearly after a delayed start (relative to the nearsurface) to $480{ }^{\circ} \mathrm{C}$ after 2.25 hours. Peeling of the stone and longitudinal cracks on the surfaces were observed. The stone did not fail explosively. Burning of the adhesive seems to have started well after an hour and stopped at short distances away from the fire. Larger stone sections may insulate the epoxy even better, towards meeting fire safety regulations.

Future work may extend to multi-strand specimens covering longer spans. Within such studies, it would be useful to investigate whether strategies such as internally anchored vertical bars may

7) For the specific eccentric-strand specimen tested in this study, three-point bending led to failure by spalling of compression stone at midspan and by formation of a dominant asymmetric crack which propagated through the stone from midspan, first at an inclination and then horizontally on reaching the level of the strand in the stone blocks. Cracking at the midspan mortar joint was delayed to about $40 \%$ of the peak load, a clear benefit of the pretensioning. Repeat tests are needed to establish whether this failure mode occurs consistently.

8) The use of concentric-strand, square section specimens to identify transfer zones and eccentric-strand, rectangular section specimens to elucidate the combined effects of pretensioning and external loads, including the effects of the mortar joints between blocks, is recommended for study of pretensioned beams comprising blocks of other types of stone.

be successful at inhibiting flexure-shear failure under different load types. Development of design principles from such work would provide the basis for safe, wide application of this promising form of low-carbon floor construction. 
651 [1] Heyman J. The Stone Skeleton. Int. J. Solids Structures, 1966, Vol. 2, 249-279.

652

653

654

655

656

657

658

659

660

661

662

663

664

665

666

667

668

669

670

671

672

673

675

676

[2] Hamoush S, et al. Development of sustainable engineered stone cladding for toughness, durability, and energy conservation. Construction and Building Materials, 2011, 25, 4006-4016.

[3] Khatib J. Sustainability of Construction Materials, 2016, $742 \mathrm{pp}$, Woodhead Publishing, $2^{\text {nd }}$ Edition, ISBN 978-0-08-100995-6.

[4] Lott G. Sourcing stone for the conservation and repair of historical buildings in Britain. Quarterly Journal of Engineering Geology and Hydrogeology, 2013, 46, 405-420.

[5] Turgut P, Yesilnacar MI, Bulut H. Physico-thermal and mechanical properties of Sanliurfa limestone, Turkey. Bulletin of Engineering Geology and the Environment, 2008, 67, 485-490.

[6] Török Á, Přrikryl R. Current methods and future trends in testing, durability analyses and provenance studies of natural stones used in historic monuments. Engineering Geology, 2010, $115,139-142$.

[7] Sorace S. Long-term tensile and bending strength of natural stones. Materials and Structures, August / September 1996, Vol. 29, 426-435.

[8] Yates T, et al. Changes in engineering properties of natural stone. Proc. ICE, Construction Materials, 2012, 165(3), 127-133.

[9] Karaca Z, Onargan T. A new approach to stone deformation : stone deformability index. Proc. ICE, Construction Materials, 2012, 165(3), 189-195.

[10] Ozguven A, Ozcelik Y. Investigation of some property changes of natural building stones exposed to fire and high heat. Construction and Building Materials, 2013, 38, 813-821.

[11] Boote S, Lynes A. Stone as a structural material. Part 1: Mechanical properties. The Structural Engineer, March 2020, 20-25.

[12]Stone Federation Great Britain. Natural stone, the oldest sustainable material. 2011, Publication Number SUS01/11.

[13] Blanchard I. The use of natural stone for internal flooring. Proc. ICE, Construction Materials, 2012, 165(3), 177-187. 
[14] Metalssi OO, et al. Experimental study on reinforced stone beams. Engineering Structures, 2013, 54, 1-8.

[15] Pedreschi R. A feasibility study of post-tensioned stone for cladding. Construction and Building Materials, 2013, 43, 225-232.

[16] Camposinhos RS. Undercut anchorage in dimension stone slab cladding. Proc. ICE, Construction Materials, 2013, 166(3), 158-174.

[17] Ye Y, Guo ZX, Chai ZL. Flexural behaviour of stone slabs reinforced with prestressed NSM CFRP bars. ASCE J. Comp. Constr, 18(4), 2014, 04014004 / 1-12.

[18] Contrafatto L, Cosenza R. Behaviour of post-installed adhesive anchors in natural stone. Construction and Building Materials, 2014, 68, 355-369.

[19] Xie J, Wu X, Xu F. Experimental study on the flexural behaviour of stone beams strengthened with a combination of angle steels and PET belts. Materials and Structures, August / September 2016, Vol. 49, 1013-1024.

[20] Ye Y, et al. Strengthening stone beams with prefabricated polymer-reinforced stone plates. Proc. ICE, Structures and Buildings, 2020, doi: 10.1680/jstbu.19.00165

[21] Boote S. Stone as a structural material. Part 2: Traditional and reinforced stone stairs. The Structural Engineer, June 2020, 18-23.

[22] Boote S, Lynes A. Stone as a structural material. Part 3: Post-tensioned stone structures. The Structural Engineer, August 2020, 22-28.

[23] Marti-Vargas JR, et al. Bond of $13 \mathrm{~mm}$ prestressing steel strands in pretensioned concrete members. Engineering Structures, 2012, 41, 403-412.

[24] Marti-Vargas JR, et al. Slip distribution model along the anchorage length of prestressing strands. Engineering Structures, 2014, 59, 674-685.

[25] Bai F, Davison JS. Composite beam theory for pretensioned concrete structures with solutions to transfer length and immediate prestress losses. Engineering Structures, 2016, 126, 739-758.

[26] Brearley LM, Johnston DW. Pull-out bond tests of epoxy-coated prestressing strand. ASCE J. Struct. Eng., 1990, 116(8), 2236-2252. 
[27] Laco J, Borzovic V. Experimental investigation of prestressing strand on bond behavior of concrete members. ACI Struct. J., 2017, 114(1), 15-24.

[28] Shin HO, et al. Bond behaviour of pretensioned strand embedded in ultra-high-performance fiber-reinforced concrete. Int. J. Conc. Str. Mat., 2018, 12.

[29] Mohandoss P, et al. Transmission length of pretensioned concrete systems - comparison of codes and test data. Mag. Conc. Res., 2019, 71(17), 881-893.

[30] https://www.polycor.com/stone/limestone/valanges/

[31] https://www.parex.co.uk/Technical_Mortars/Grouts/Epoxy_Resin_Based

[32] Little JA, Mann BP. Optimizing logarithmic decrement damping estimation through uncertainty propagation, Journal of Sound and Vibrations, 2019, 457, 368-376.

[33] Sarhat S, Sherwood EG. Shear Strength of GFRP-Reinforced Concrete Masonry Beams. In ASTM International Selected Technical Papers: Masonry 2018, STP 1612, Ed. Krogstad NV \& McGinley M. 131-157.

(1)

(1)

(1)

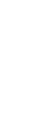

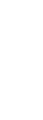

2




\begin{tabular}{|c|c|c|c|}
\hline $\begin{array}{c}\text { Global or } \\
\text { Local? }\end{array}$ & Figure & $\begin{array}{c}\mathrm{E} \\
\left(\mathrm{kN} / \mathrm{mm}^{2}\right)\end{array}$ & Notes \\
\hline Local & Fig. 6(b) & 28.4 & Average axial strain in concentric-strand specimen at jacking stage \\
\hline Global & Fig. 7(b) & 29.1 & Free vibration of pre-tensioned concentric-strand specimen \\
\hline Global & Fig. 10(a) & 28.8 & Midspan upward deflection of eccentric-strand specimen due to jacking \\
\hline Local & Fig. 10(b) & 29.4 & Net strain at soffit of eccentric-strand specimen due to jacking \\
\hline \multicolumn{4}{|c|}{ Mean $E$ value $=28.9 \mathrm{kN} / \mathrm{mm}^{2}: \mathrm{CoV}=1.3 \%$} \\
\hline
\end{tabular}




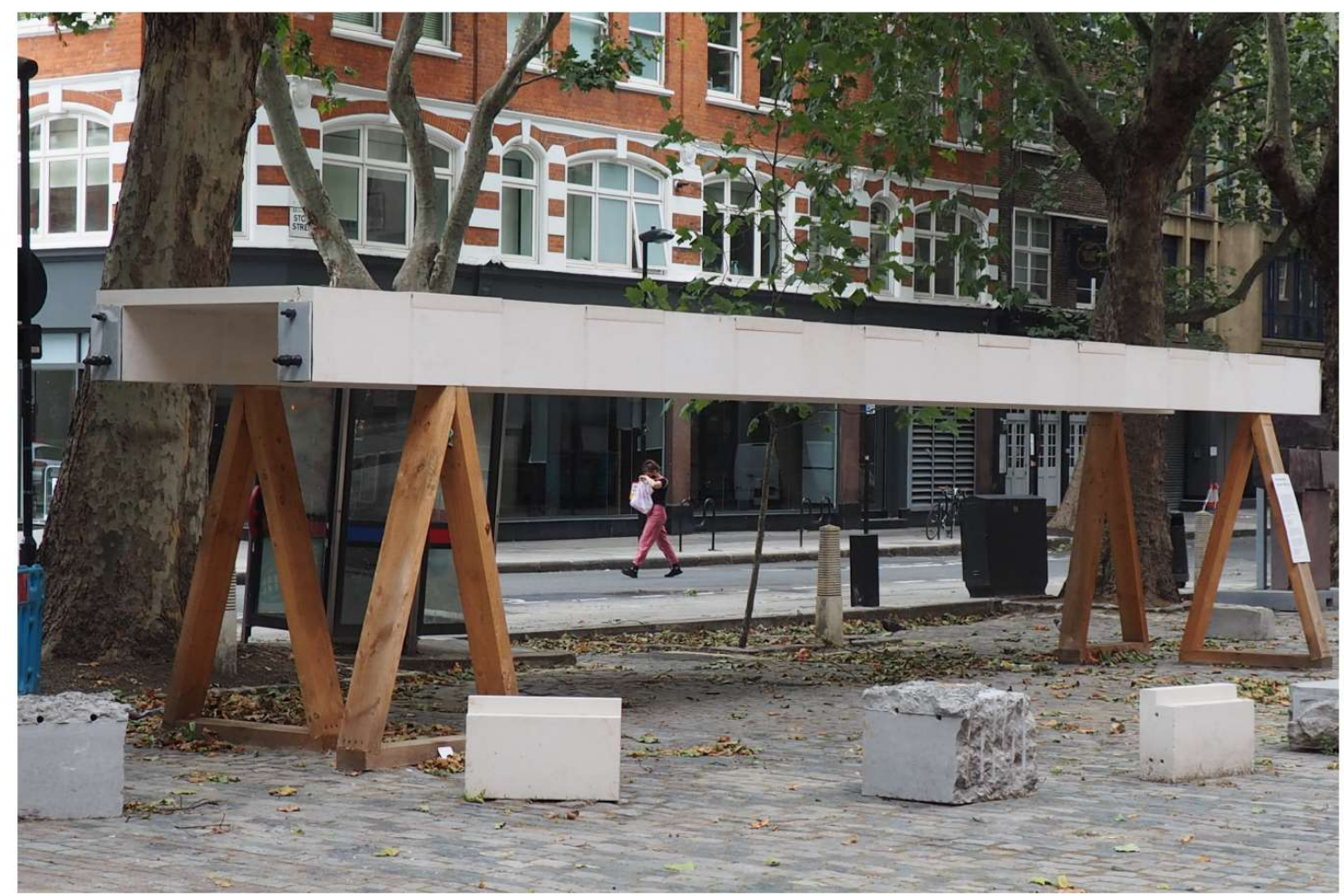

(a) $12 \mathrm{~m}$ Long Post-tensioned Limestone Floor Beams

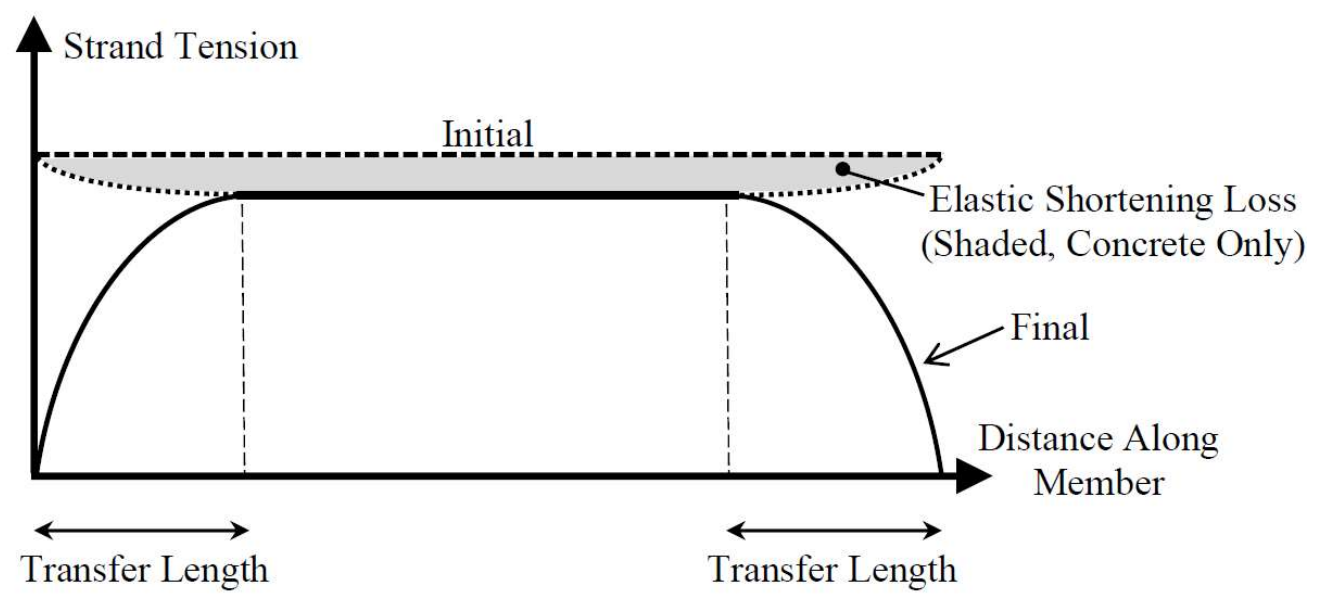

(b) Strand Force Profiles Along Member During Pretensioning 


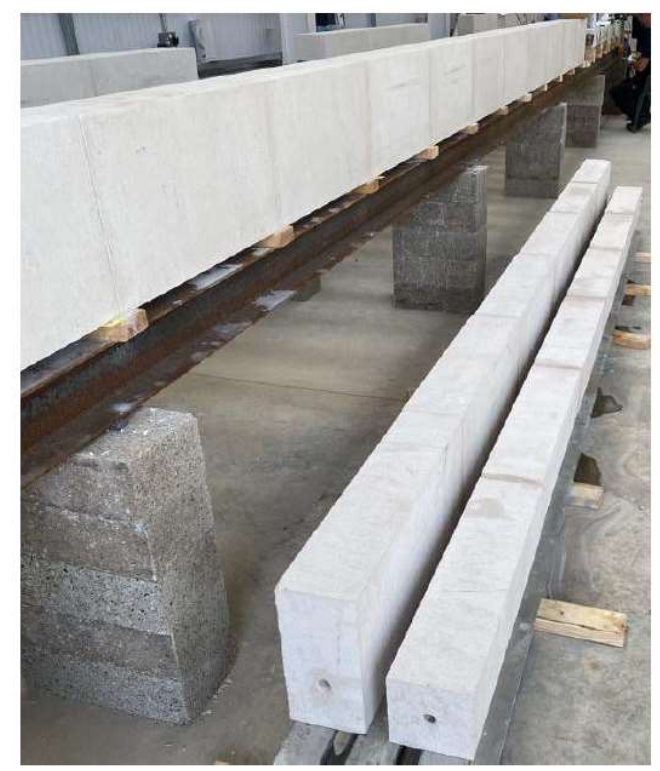

(a) Valange limestone blocks assembled into specimens

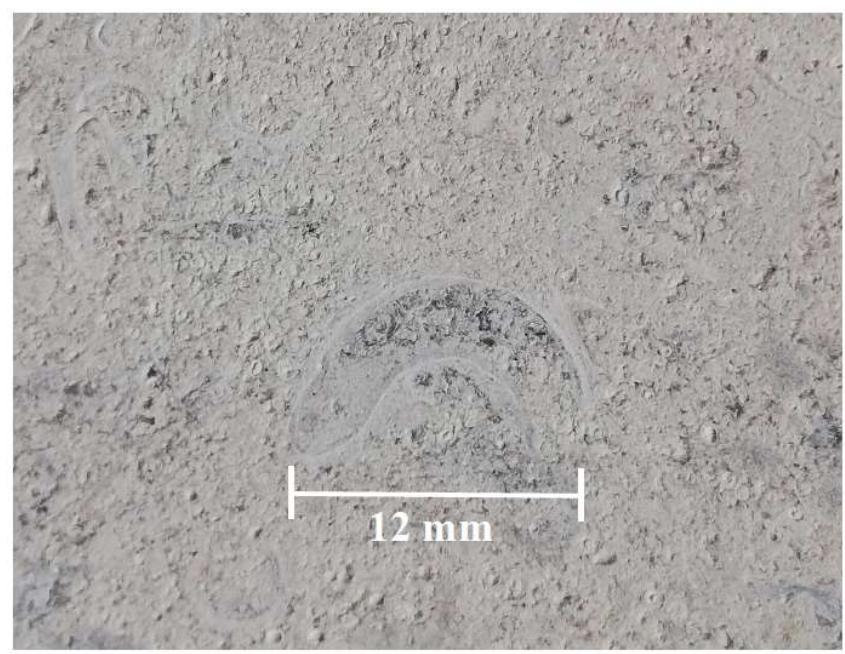

(b) Cut surface revealing C-shaped fossil fragment

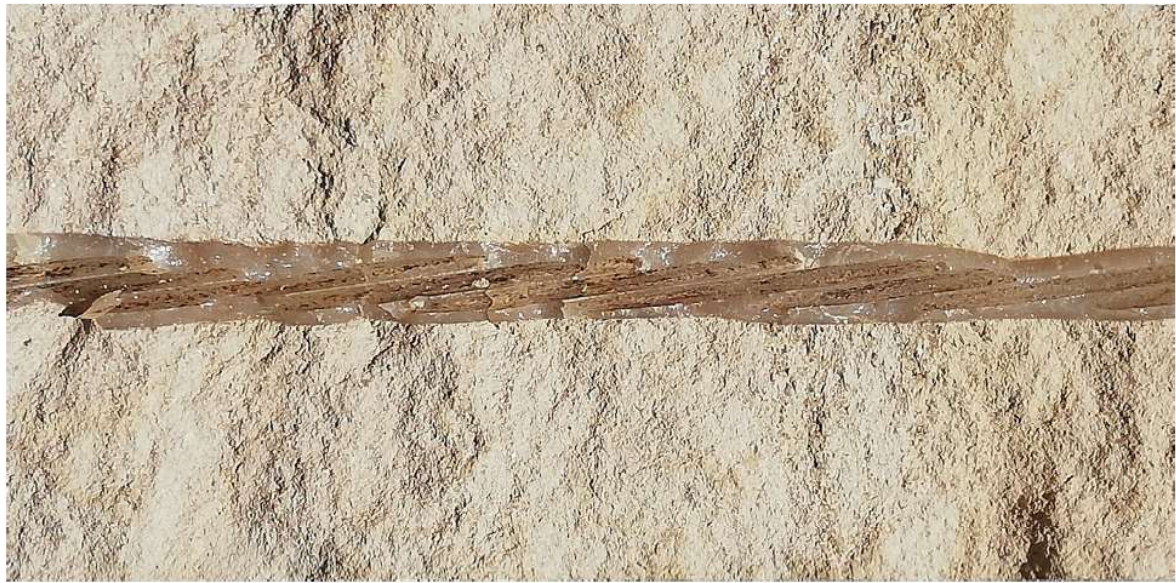

(c) Post-test sample from beam showing cured epoxy that enclosed half of strand section 


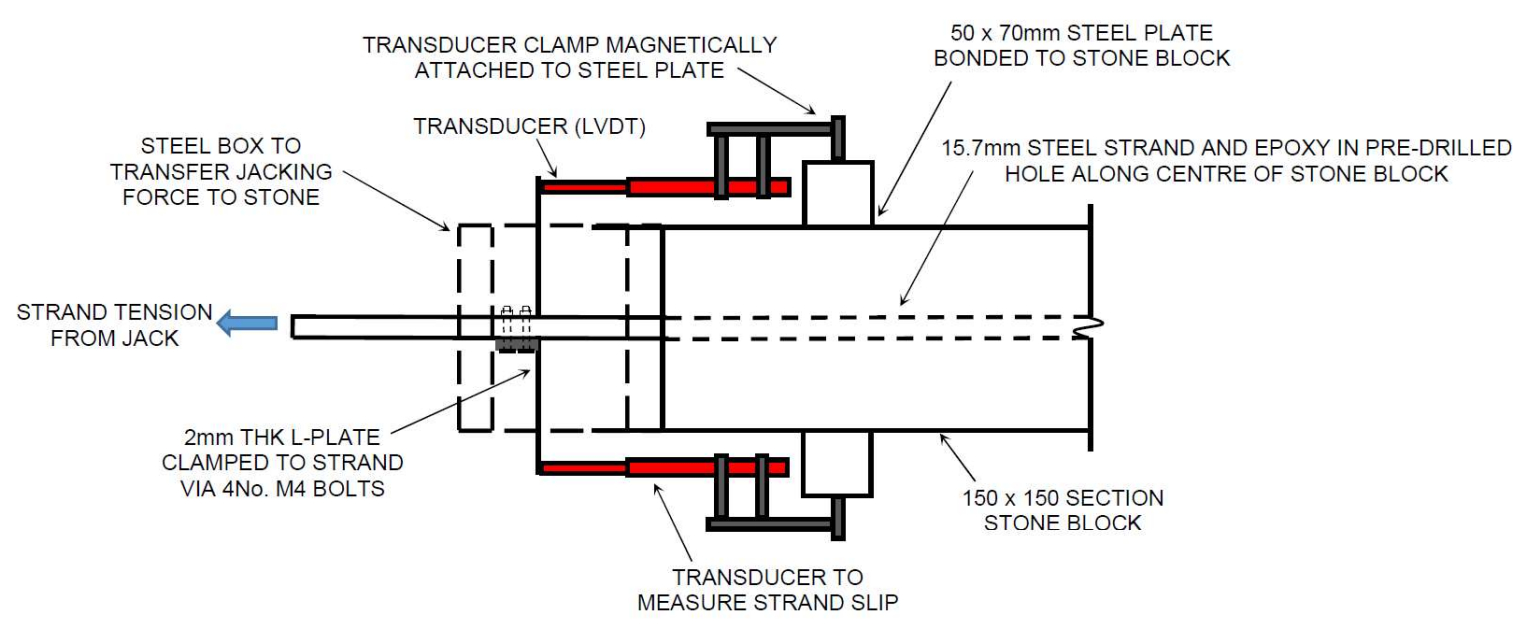

(a) Plan View at Jacking End

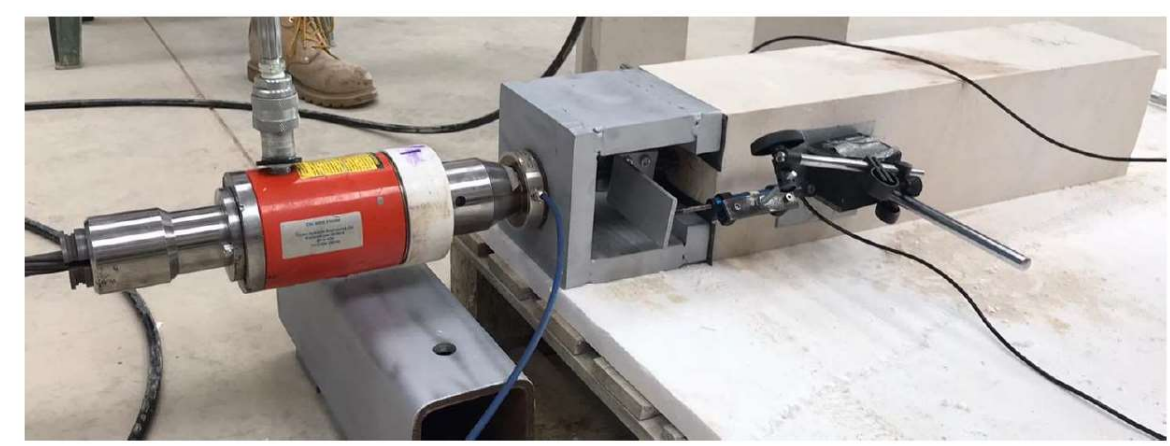

(b) Test Setup for Specimen P600

Fig. 3 - Pullout Test Setup 

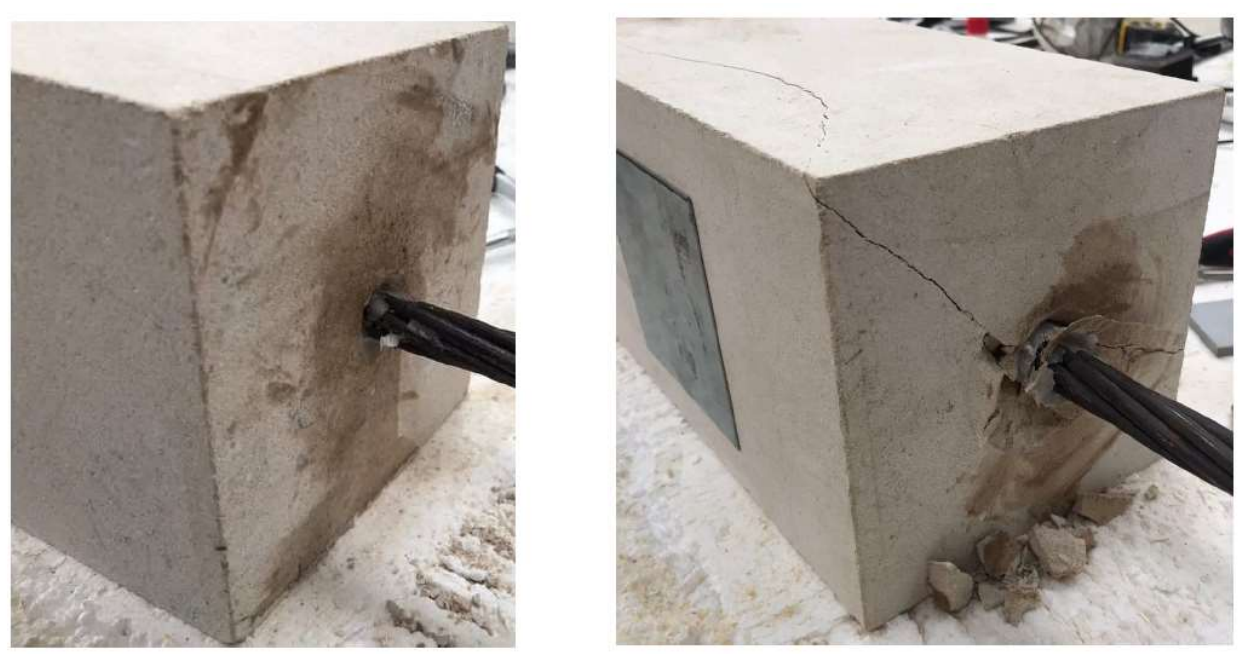

(a) Failure of Specimens P400 (Left) and P600

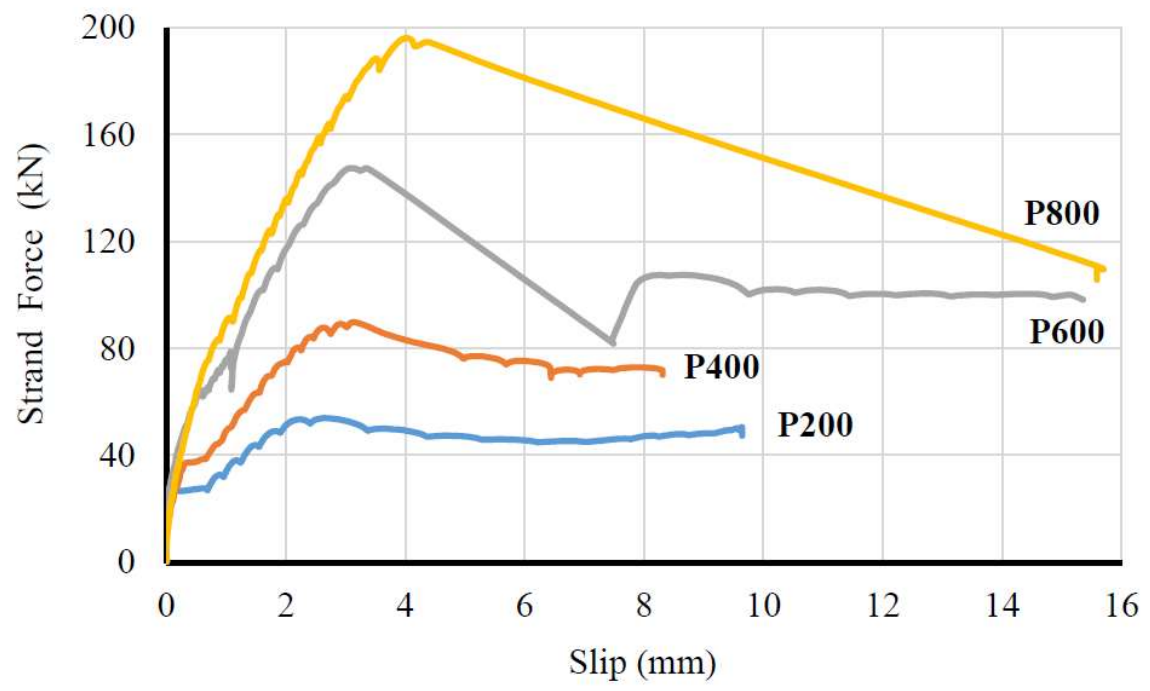

(b) Strand Force vs Slip Characteristics

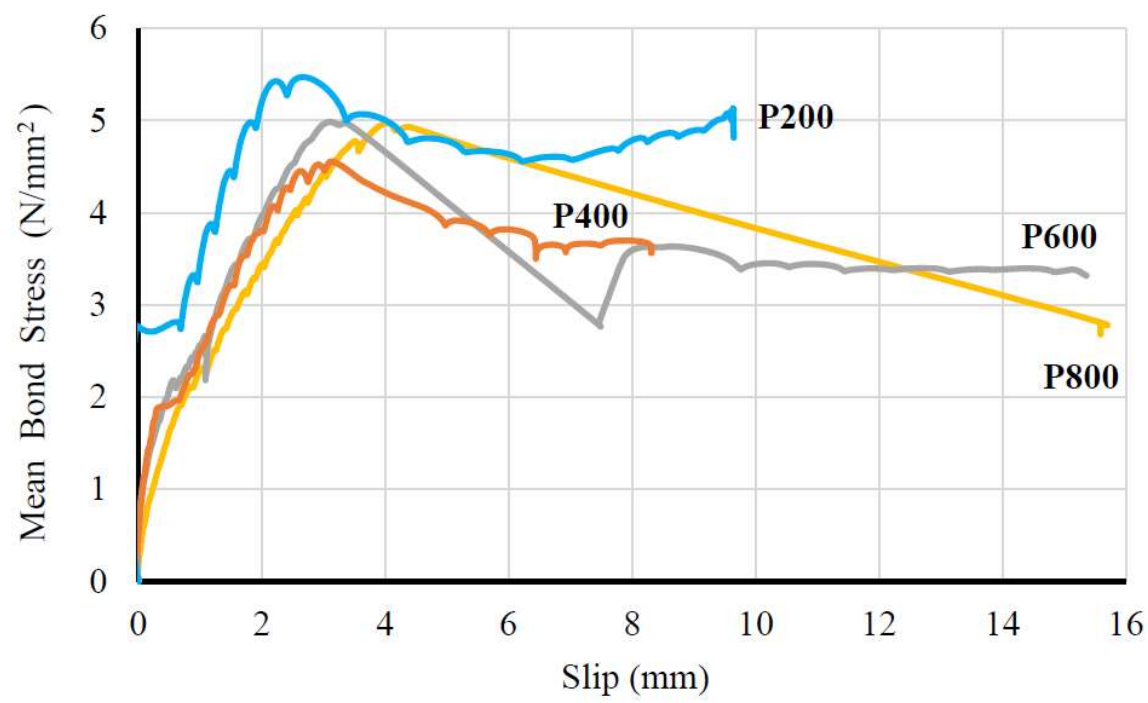

(c) Variation of Mean Shear Bond Stress with Slip 
765

766

767

768

769

770

771

772

773

774

775

776

777

778

779

780

781

782

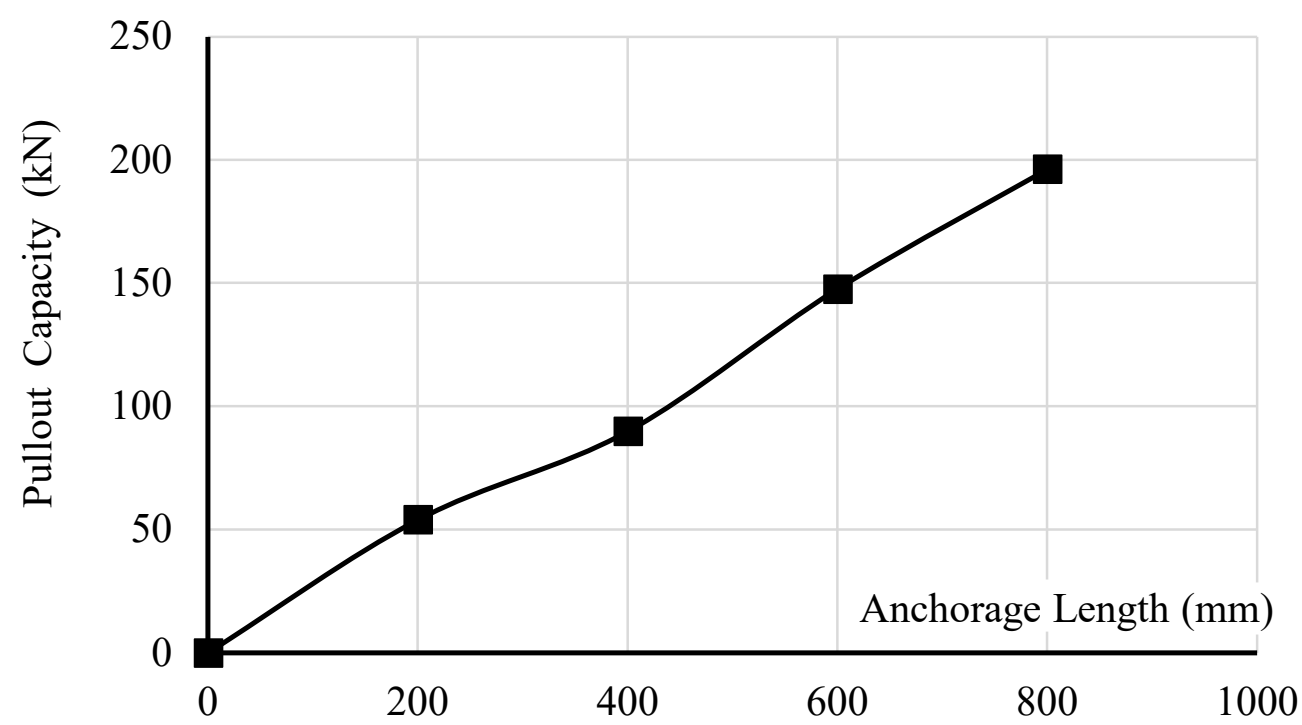

(a) Variation of Pullout Failure Load with Embedment Length

Fig. 4 - Pullout Test Results 


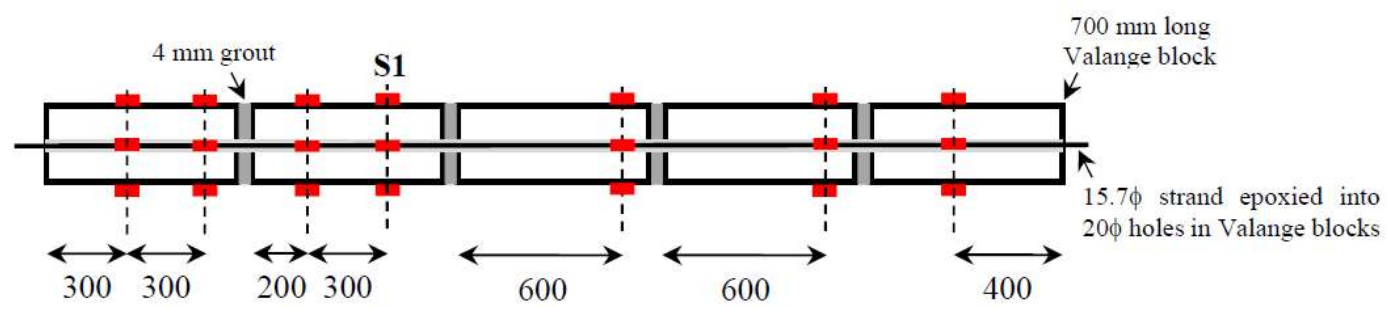

(a) Plan

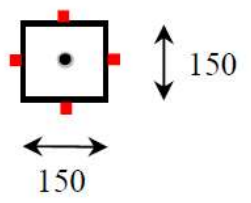

(b) Section

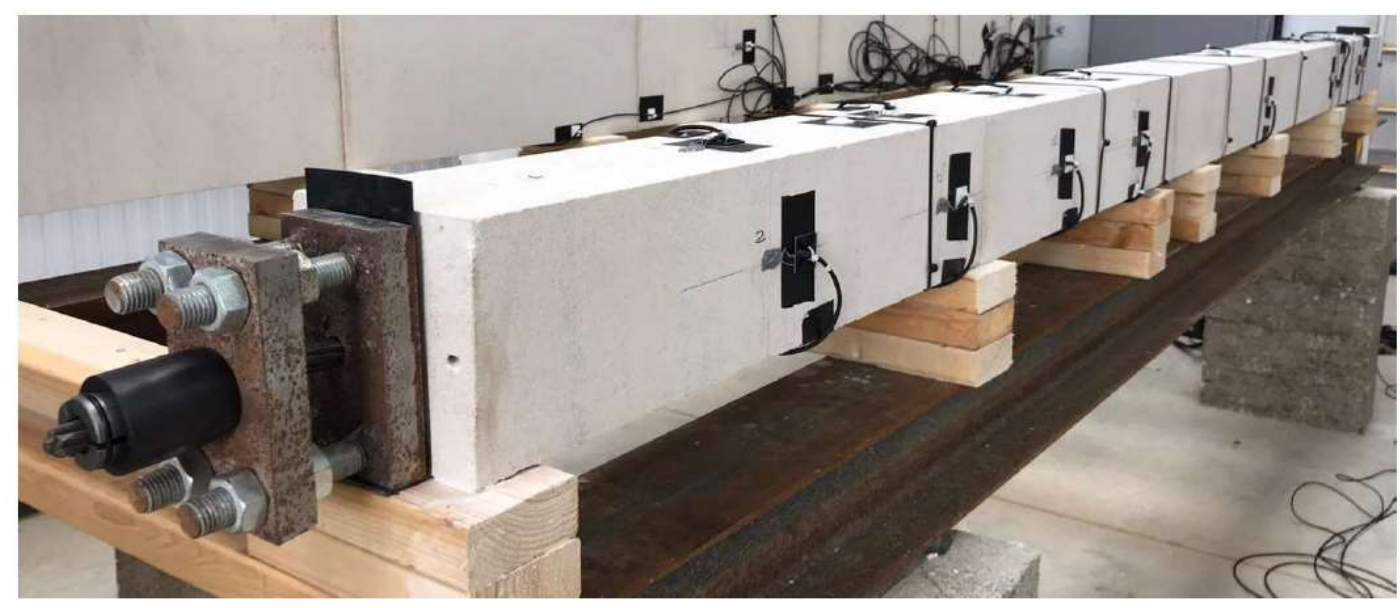

(c) Tensioning stage at anchored end

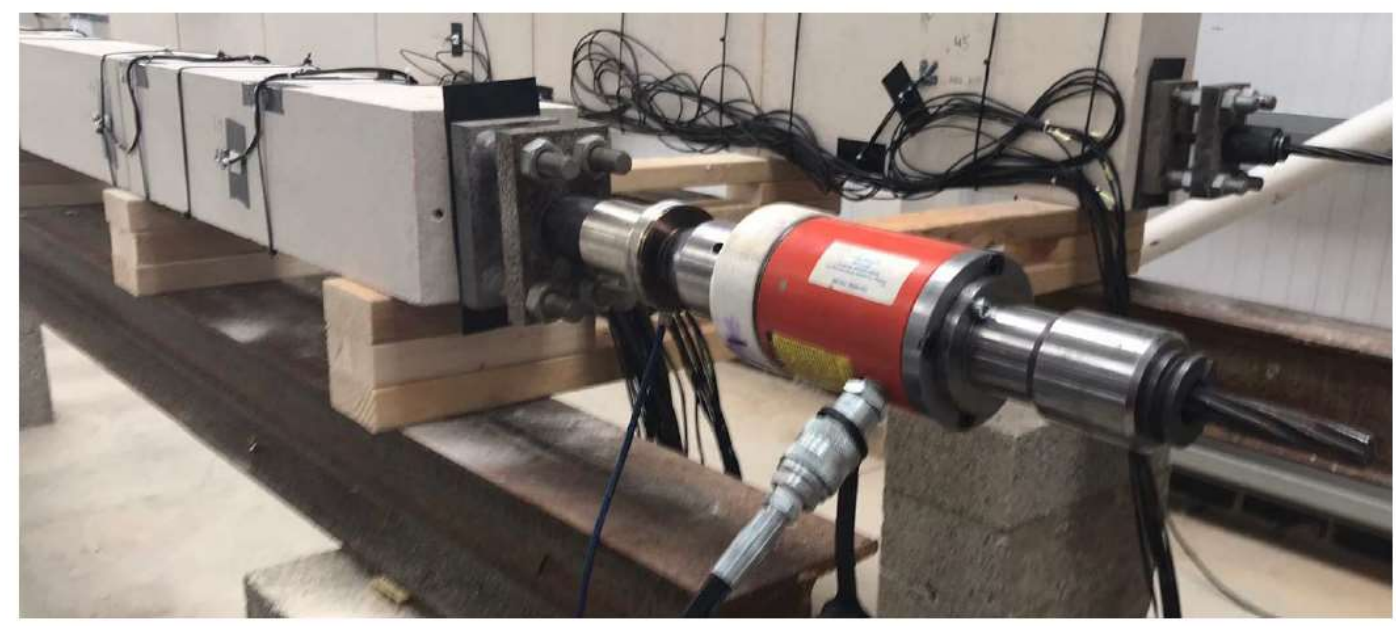

(d) Tensioning stage at jacking end

Fig. 5 - Prestressing setup for concentric-strand specimen 


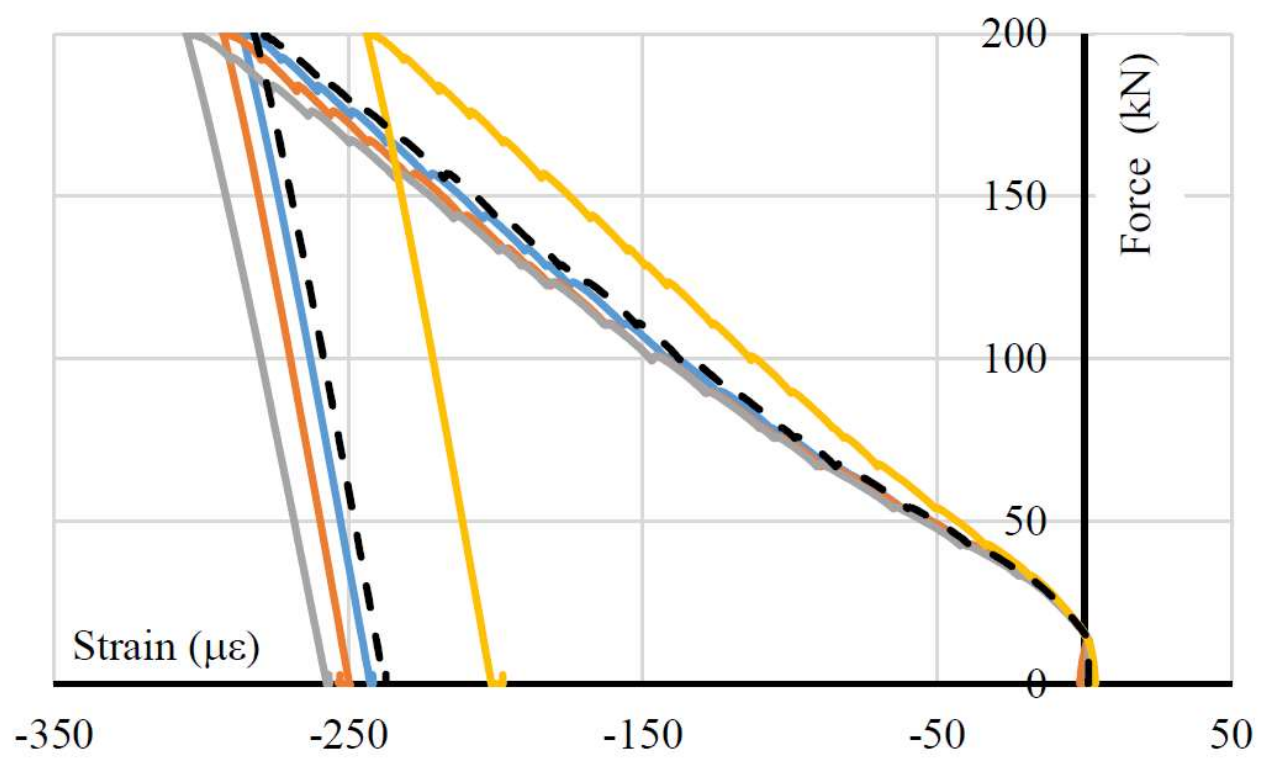

(a) Individual and mean strains at section S1 (Fig. 5(a)) during tensioning stage

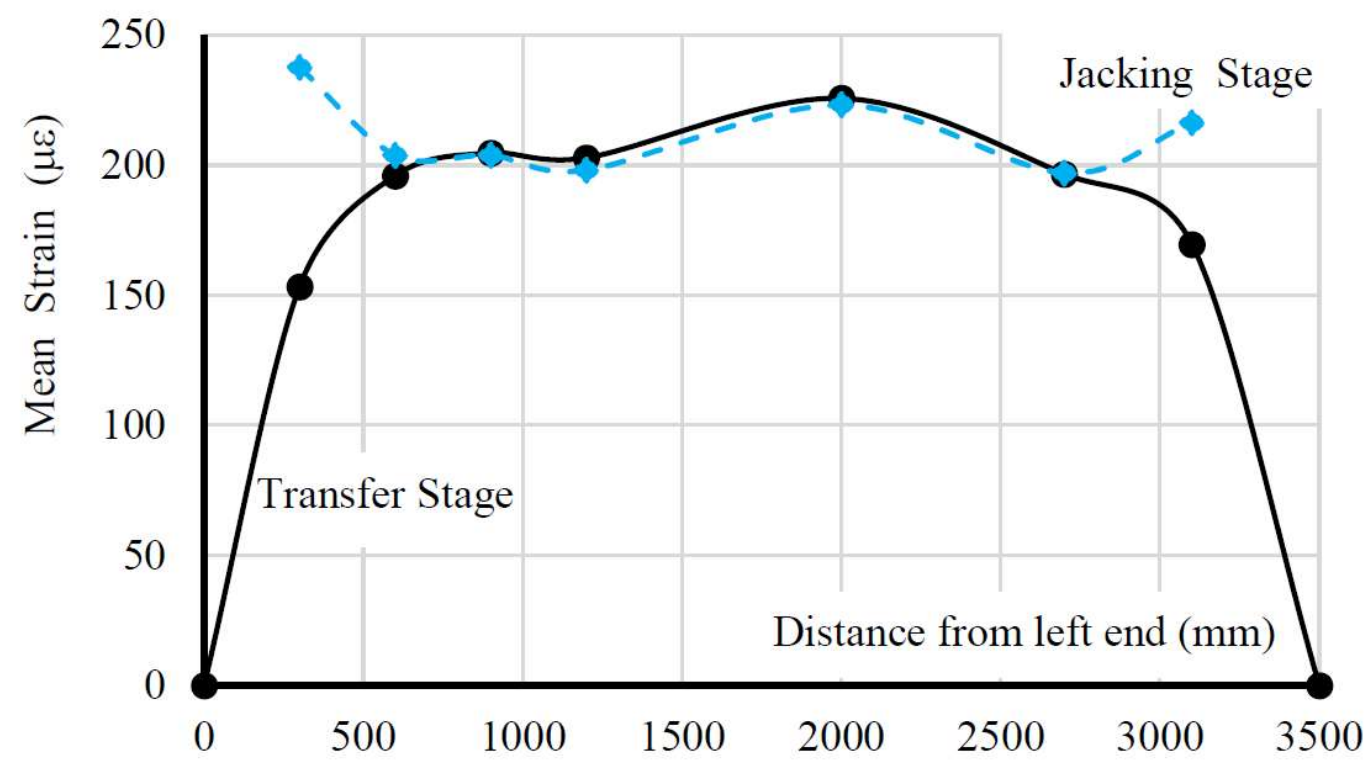

(b) Section mean compressive strains (absolute values) along specimen after release Fig. 6 - Strain response during pretensioning of concentric-strand specimen 


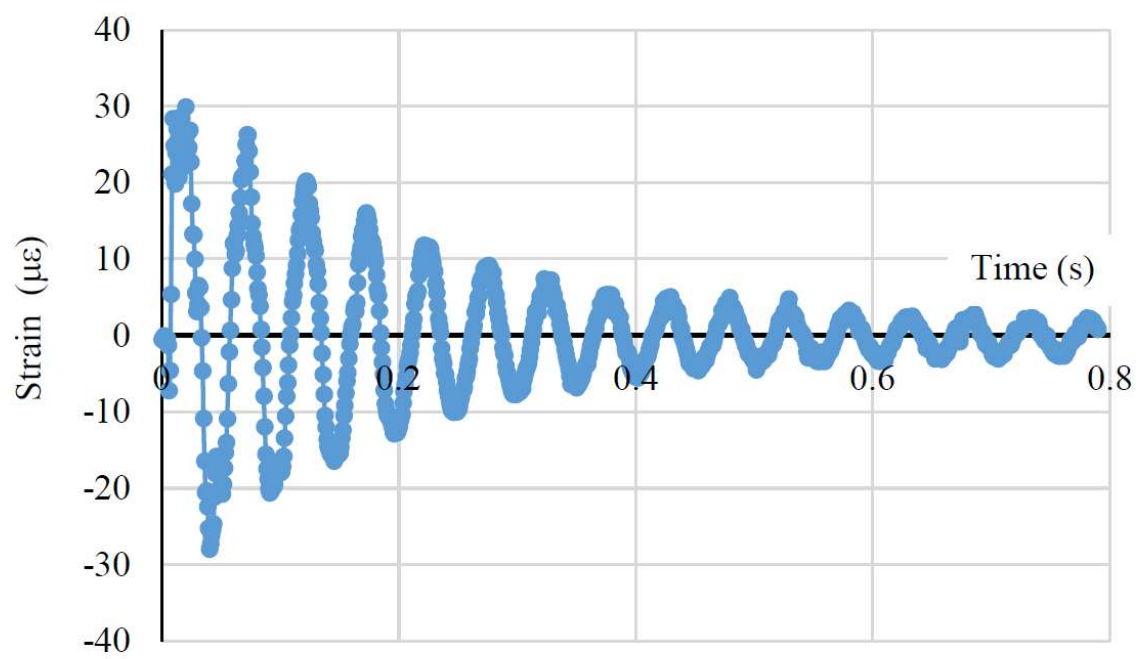

(a) Free vibration strain-time plot for concentric-strand specimen

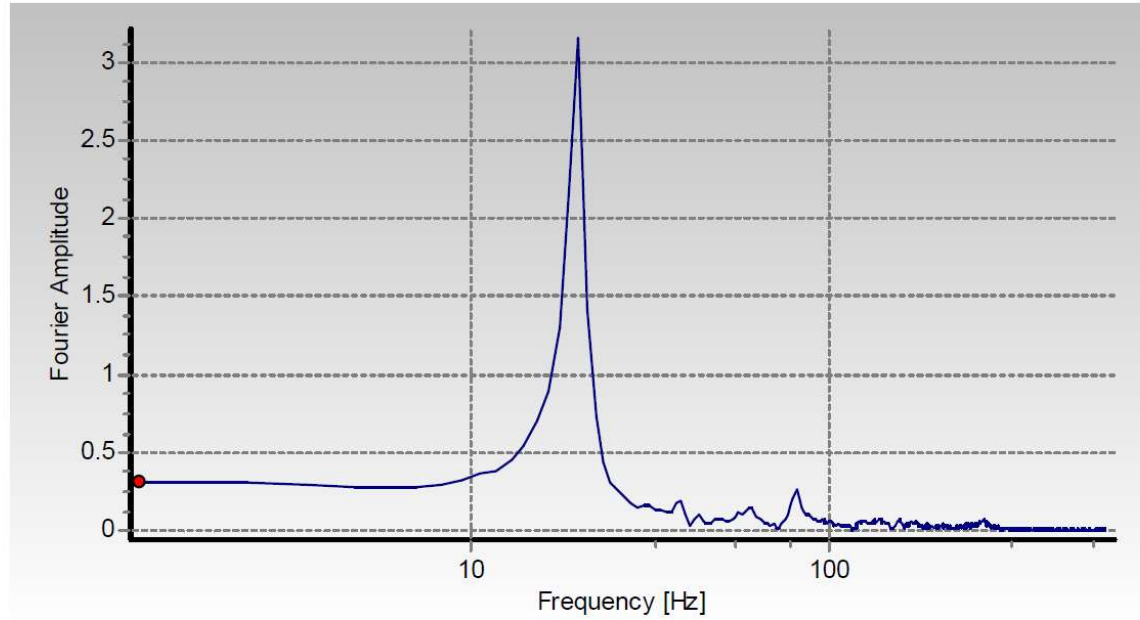

(b) Fast Fourier Transform for concentric-strand specimen

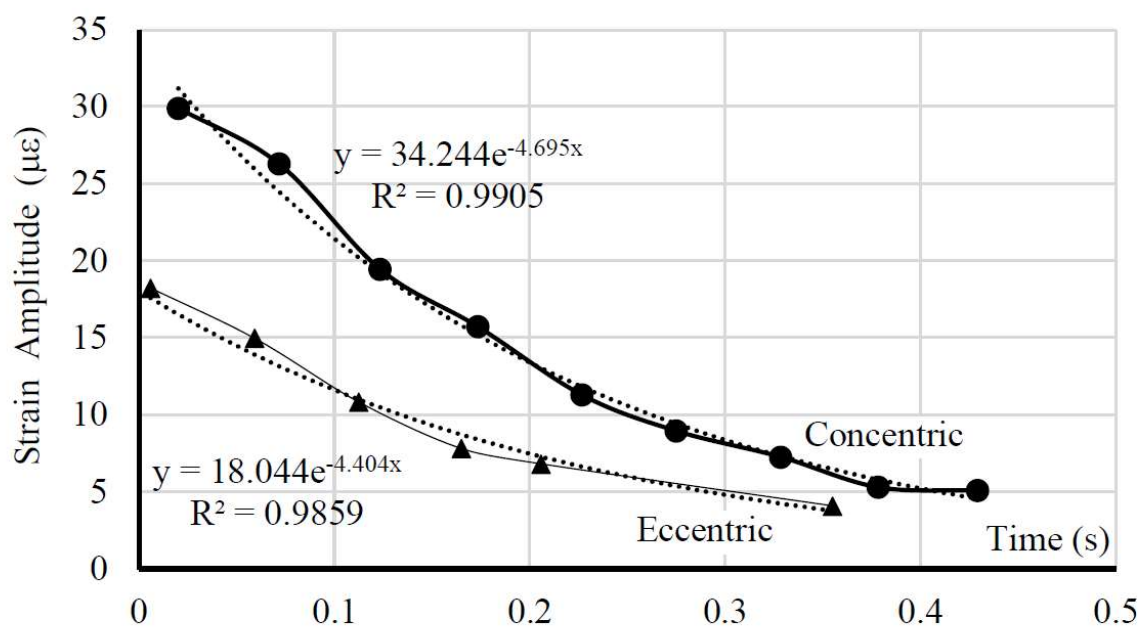

(c) Vibration decay for eccentric-strand and concentric-strand specimens

Fig. 7 - Vibration Test Results 


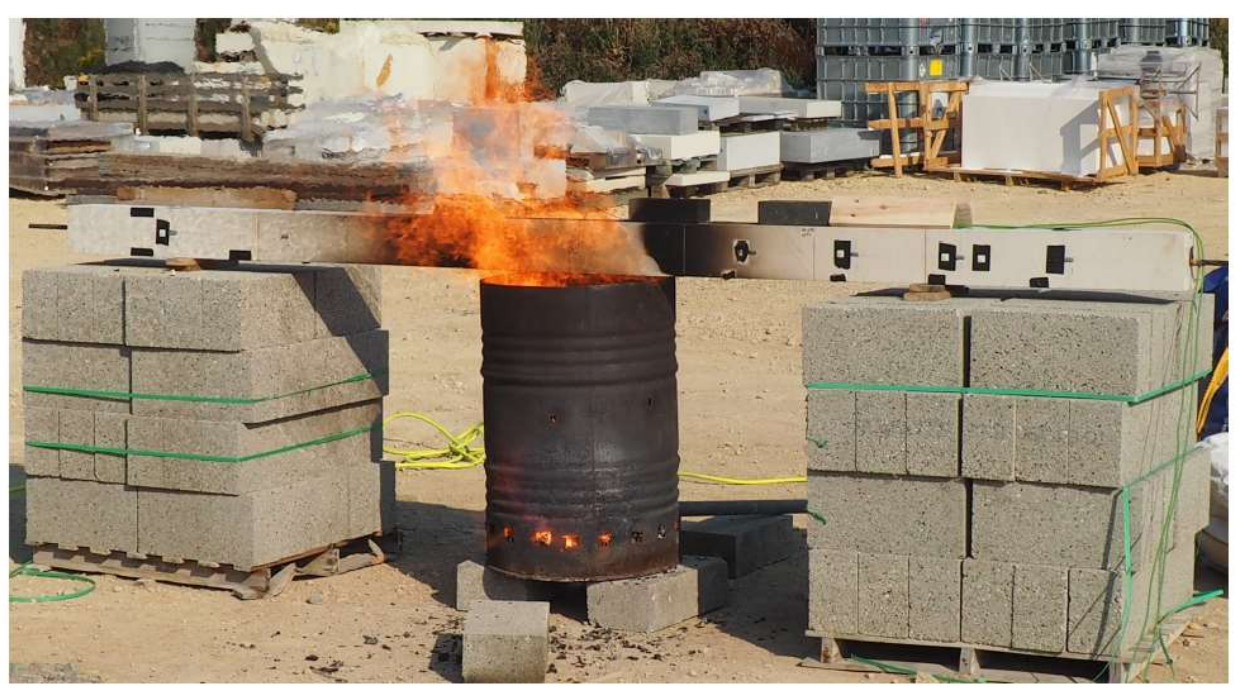

(a) Fire Test in Progress

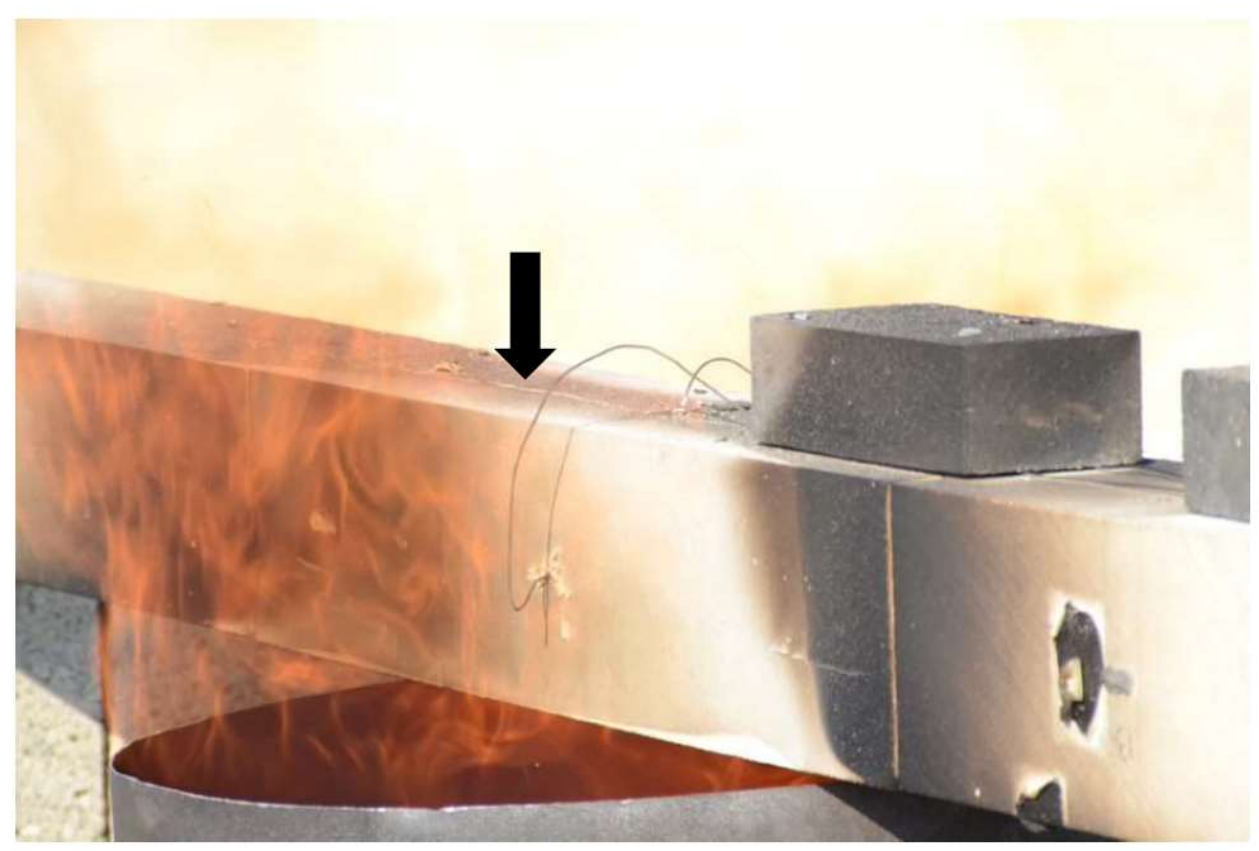

(b) Longitudinal crack on top face during fire

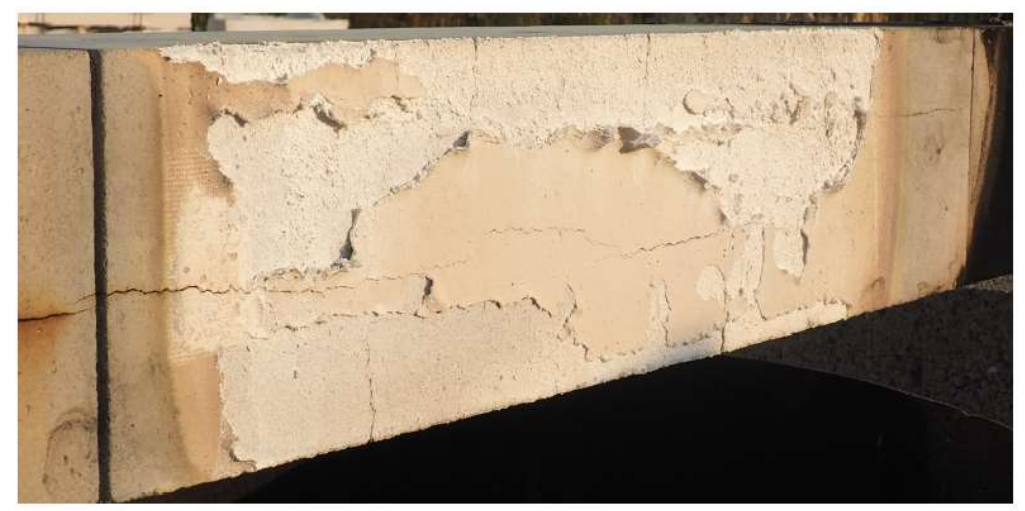

(c) Bottom Face Post Fire : Stone Peeling 


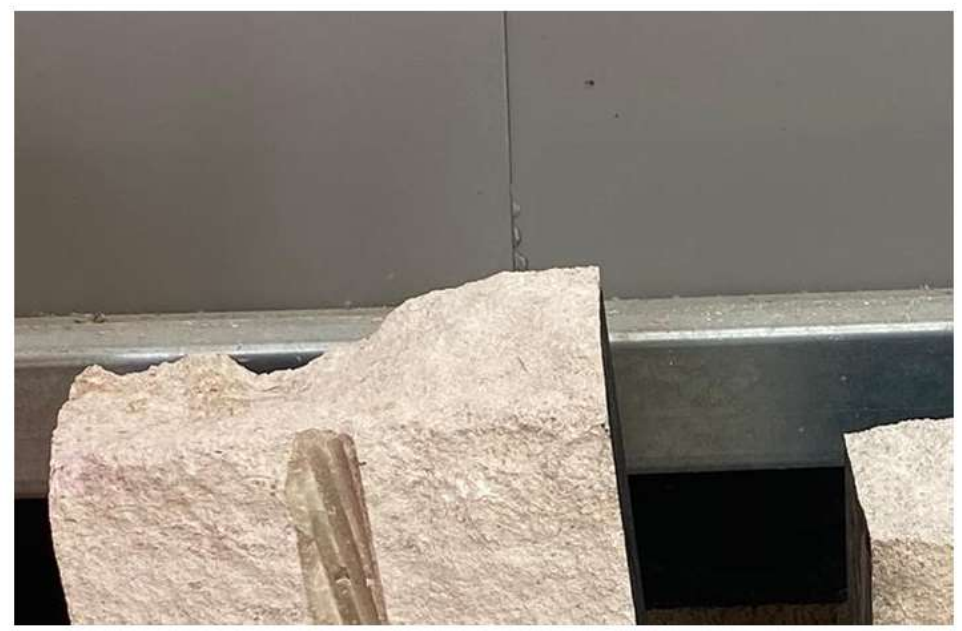

(d) Adhesive Intact (left), Burnt or Degraded (right)

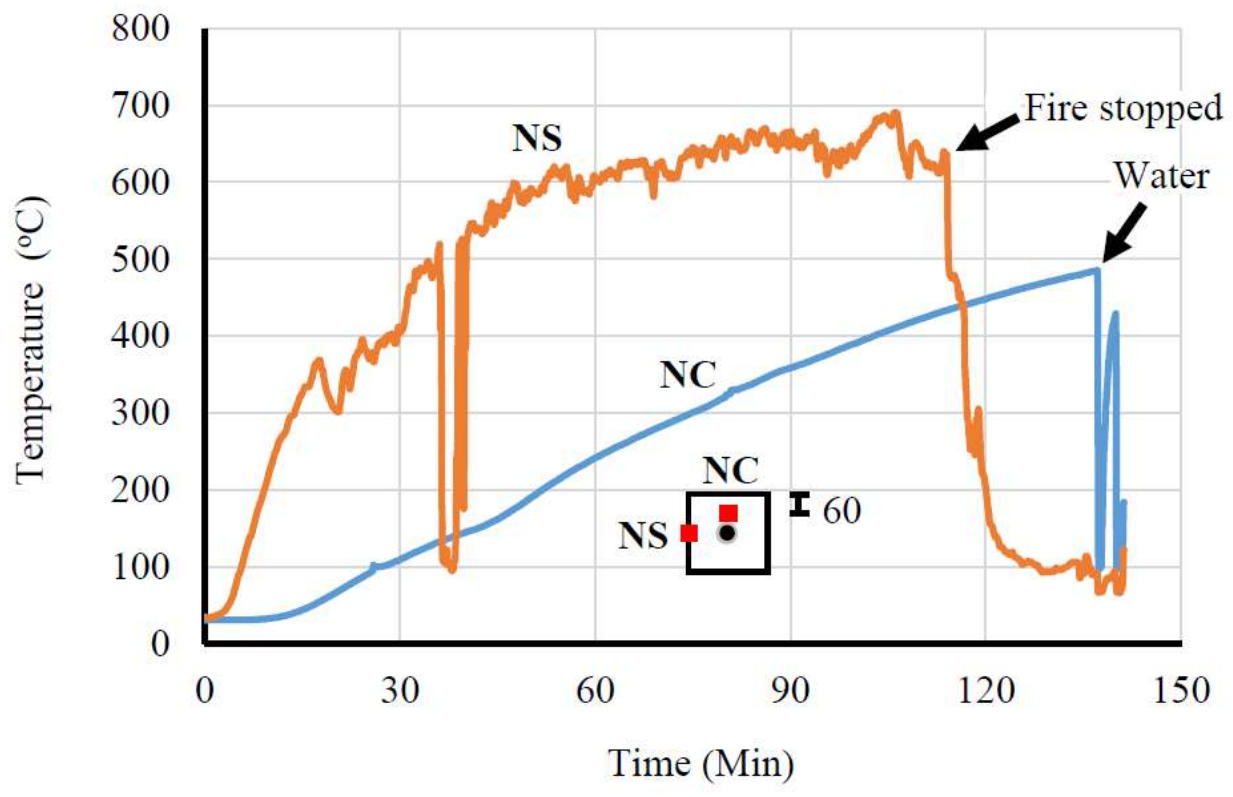

(e) Measured Temperature Variations Over Time

Fig. 8 - Fire Test Results 


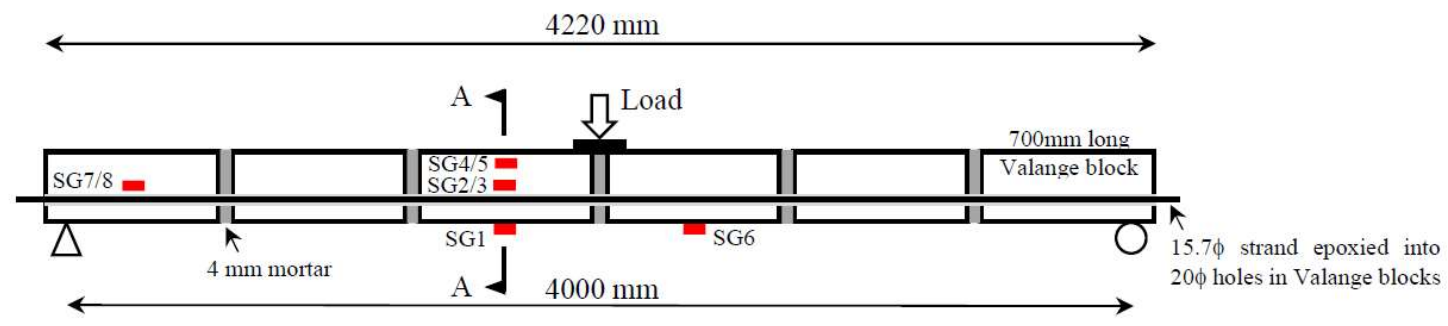

(a) Elevation

SGn - Strain Gauge n

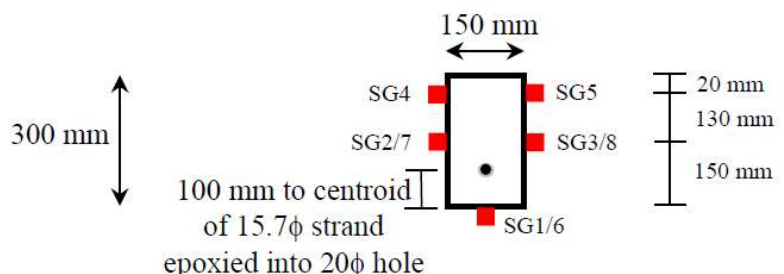

(b) Section A-A

Fig. 9 - Load and Instrumentation Setup for One Pre-tensioned Valange Stone Beam

801

802

803

804

805

806

807

808 


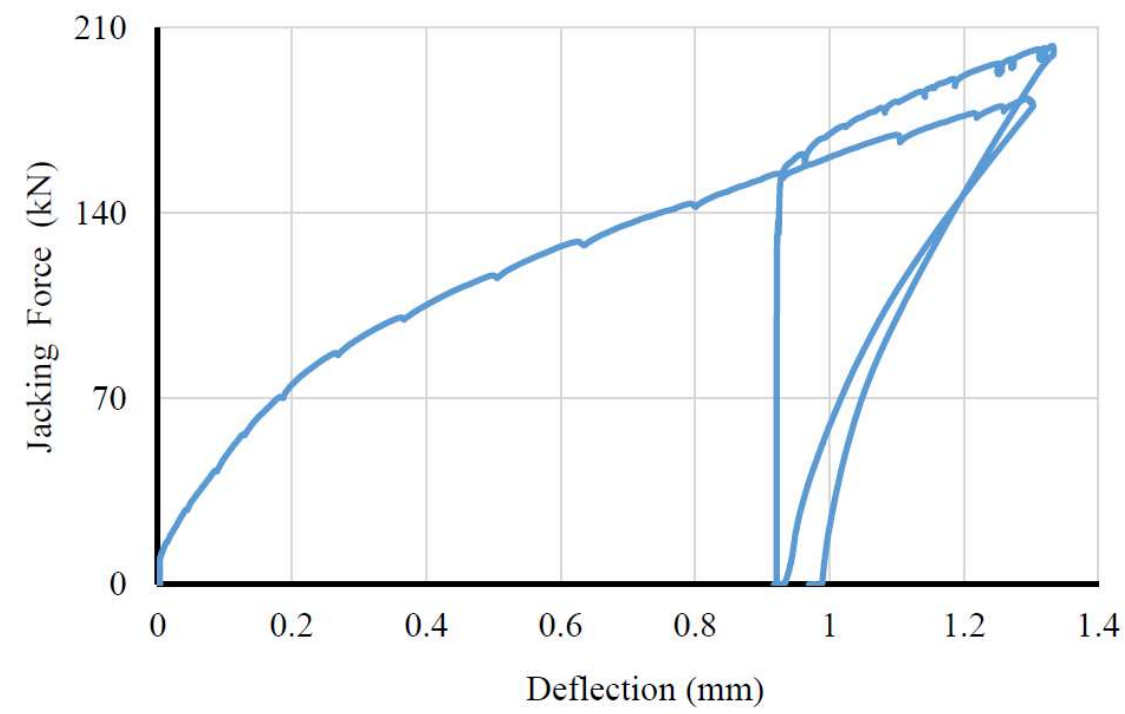

(a) Variation with jacking force of midspan upward deflection

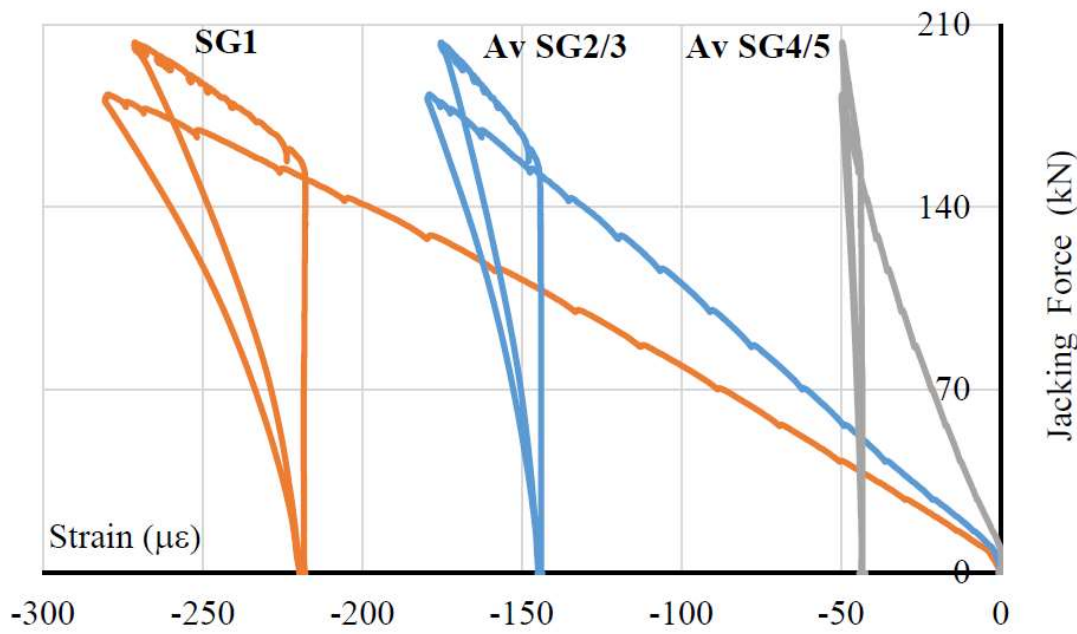

(b) Variations with jacking force of near-midspan strains at three levels

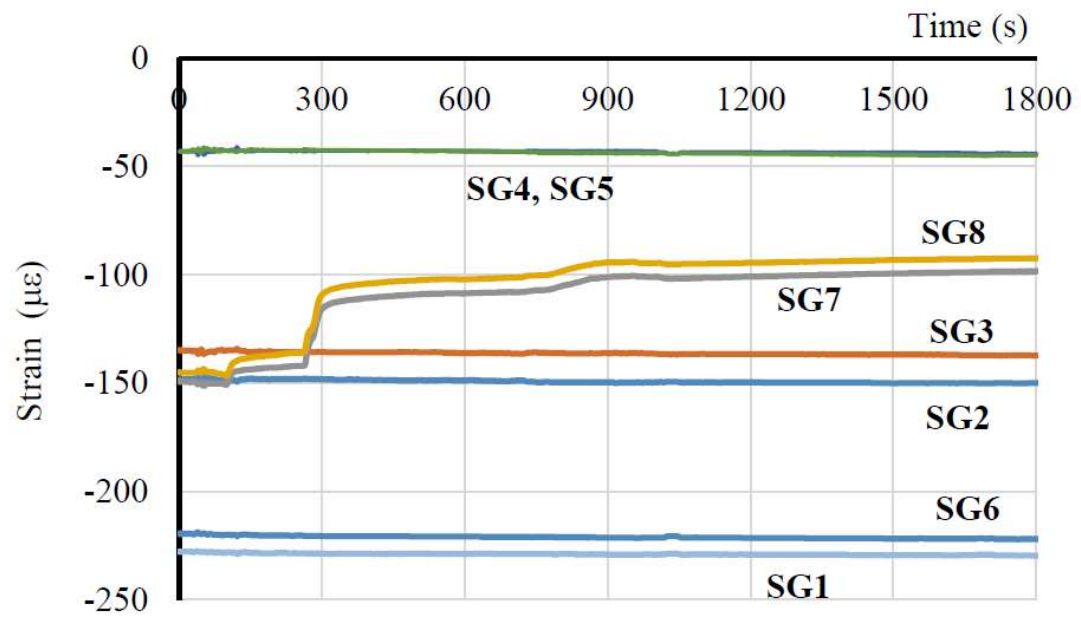

(c) Effect of release on strains 


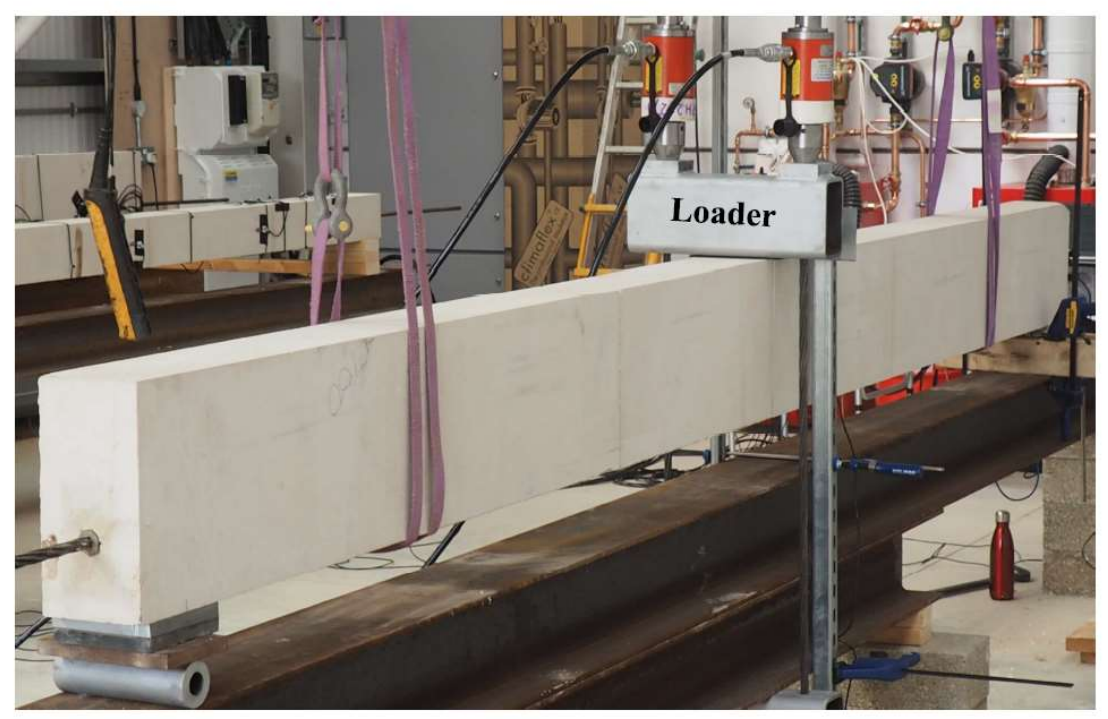

(a) Test setup

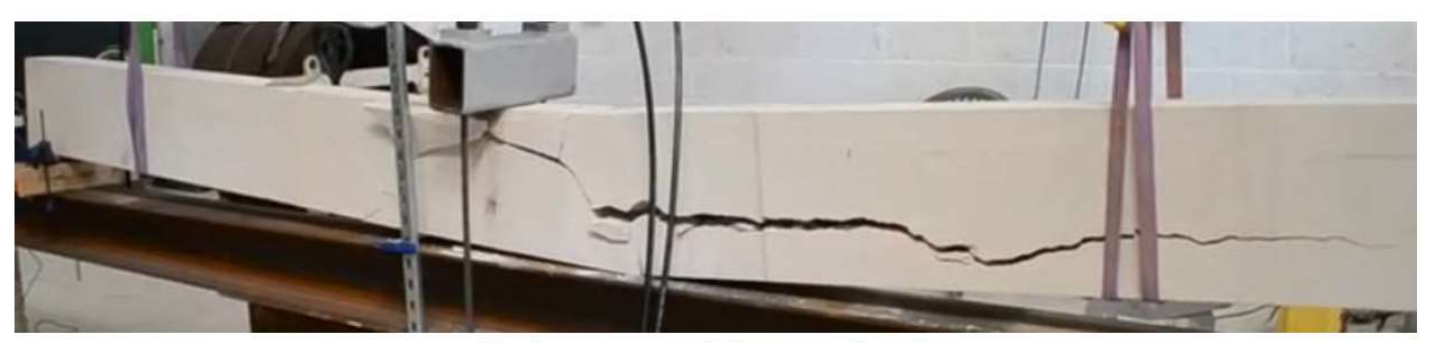

(b) Asymmetric failure crack trajectory

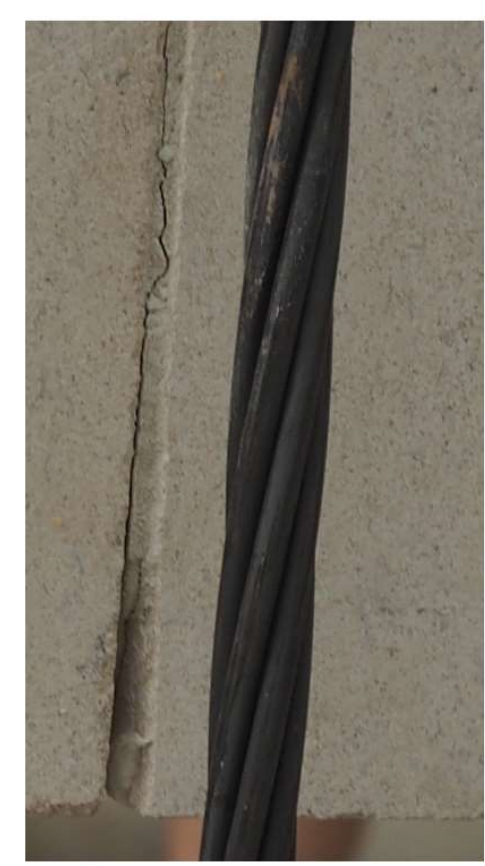

(c) Separation (crack) at mortar-stone interface at midspan 


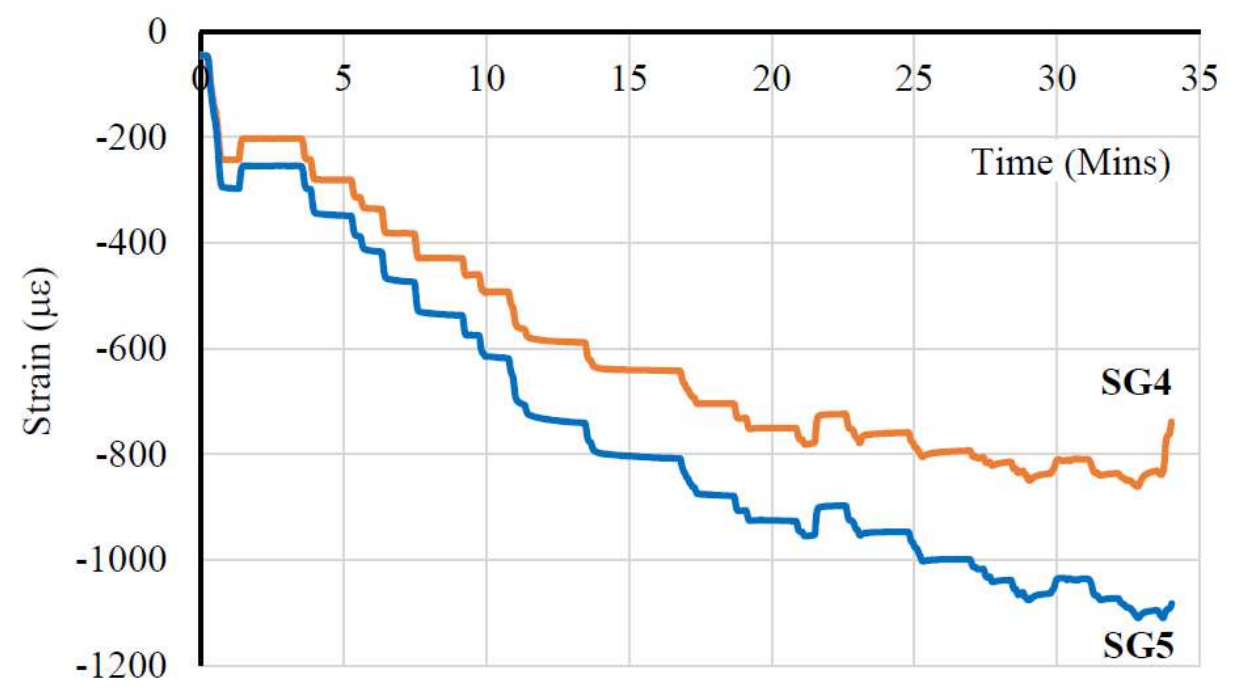

NB - See Fig. 9 for locations of strain gauges SG4, SG5

Fig. 12 - Eccentric-strand specimen : near-midspan top level strain variations with time 